Applied Physiology, Nutrition, and Metabolism

Canadian Science Publishing Physiologie appliquée, nutrition et métabolisme

\title{
A comparative study on the effects of high-fat diet and endurance training on the PGC-1a-FNDC5/irisin pathway in obese and non-obese male C57BL/ 6 mice
}

\begin{tabular}{|c|c|}
\hline Journal: & Applied Physiology, Nutrition, and Metabolism \\
\hline Manuscript ID & apnm-2017-0614.R2 \\
\hline Manuscript Type: & Article \\
\hline Date Submitted by the Author: & 04-Jan-2018 \\
\hline Complete List of Authors: & $\begin{array}{l}\text { Kazeminasab, Fatemeh; University of Isfahan } \\
\text { Marandi, Sayed Mohammad; University of Isfahan, Exercise Physiology } \\
\text { Ghaedi, Kamran; University of Isfahan } \\
\text { Safaeinejad, Zahra; Royan Institute } \\
\text { Esfarjani, Fahimeh; University of Isfahan } \\
\text { Nasr-Esfahani, Mohammad Hossein; Royan Institute }\end{array}$ \\
\hline Keyword: & $\begin{array}{l}\text { endurance training }<\text { exercise, Fndc5, High-fat diet, Irisin, obesity }< \\
\text { obesity }\end{array}$ \\
\hline $\begin{array}{r}\text { Is the invited manuscript for } \\
\text { consideration in a Special } \\
\text { Issue? : }\end{array}$ & N/A \\
\hline
\end{tabular}

SCHOLARONE ${ }^{m}$

Manuscripts 


\section{2nd Revised manuscript submission (apnm-2017-0614)}

Running title: High-fat diet and endurance training effect.

Manuscript Title: A comparative study on the effects of high-fat diet and endurance training on the PGC-1 $\alpha$-FNDC5/irisin pathway in obese and non-obese male C57BL/6 mice.

Fatemeh Kazeminasab $^{1+}$, Sayed Mohammad Marandi ${ }^{1 \dagger}$, Kamran Ghaedi ${ }^{2,3 \dagger}$, Zahra

Safaeinejad ${ }^{3}$, Fahimeh Esfarjani ${ }^{1}$, Mohammad Hossein Nasr-Esfahani $^{3 \dagger}$

${ }^{1}$ Department of Exercise Physiology, Faculty of Sport Sciences, University of Isfahan, Isfahan, Iran.

${ }^{2}$ Department of Biology, Faculty of Sciences, University of Isfahan, Isfahan, Iran.

${ }^{3}$ Department of Cellular Biotechnology, Cell Sciences Research Center, Royan Institute for Biotechnology, ACECR, Isfahan, Iran.

$+\mathrm{PhD}$ candidate of Exercise Physiology

$\dagger$ Co-Corresponding address:

Prof. Sayed Mohammad Marandi, Department of Exercise Physiology, Faculty of Sport Sciences, University of Isfahan, Hezar Jerib Ave., Azadi Sq., P.O. Box: 81799-54359, Isfahan, Iran. Tel: +98-313-7932358; Fax no: +98-313-6687572. Email:

s.m.marandi@spr.ui.ac.ir.

And

Prof. Kamran Ghaedi and Prof. Mohammad Hossein Nasr-Esfahani, Department of Cellular Biotechnology, Cell Science Research Center, Royan Institute for Biotechnology, ACECR, Royan St., Salman St., Khorasgan, P.O. Code: 816513-1378, Isfahan, Iran. Tel: +98-3195015694; fax: +98-319-5015687. Email: kamranghaedi@royaninstitute.org and mh.nasresfahani@royaninstitute.org. 


\section{ABSTRACT:}

The present study was performed to clarify how a combined exercise/diet treatment could affect the expression level of the muscle Fndc5 with respect to the body fat mass.

Male C57BL/6 mice were divided into 2 groups including low-fat (LF) and high-fat (HF) diets for 12 weeks. Then, LF fed (non-obese) and HF fed mice (obese), were divided into 4 groups: HF-Exercise, HF-Sedentary, LF-Exercise and LF-Sedentary. The exercise group received exercise, on a motor-driven treadmill for $45 \mathrm{~min} /$ day, 5 days/week during 8 weeks. Mice were sacrificed 24 hours after the final exercise session. Gastrocnemius muscle and the visceral adipose tissue were excised and frozen for the assessment of Pgc-1 $\alpha$ and Fndc5 mRNA and protein levels.

Data indicated that protein level of muscle PGC-1 $\alpha$ was decreased in HF vs LF groups and in obese vs non-obese mice. Moreover, Fndc 5 mRNA levels were increased in the muscle tissue of HF vs LF groups and, in obese vs non-obese mice. Also, in the gastrocnemius skeletal muscle, protein levels of FNDC5 were significantly higher in the high-fat fed mice, as compared to their low-fat fed counterparts, similar to what was observed for exercised vs sedentary mice.

Overall, we found that the high fat diet increased Fndc5 transcript levels in the skeletal muscle, but exercise had a minimal effect on the transcript level of Fndc5, whereas endurance training increased the protein content of FNDC5 in the skeletal muscle.

Keywords: Endurance training; Fndc5; High-fat diet; Irisin; Obesity. 


\begin{abstract}
Abstrait :
La présente étude a pour but de clarifier comment un traitement combiné d'exercice/régime pourrait affecter le niveau d'expression du muscle Fndc5 par rapport à la masse grasse corporelle.
\end{abstract}

Les souris mâles C57BL/6 ont été divisées en 2groupes: régime faible en gras (FG) et régime riche en gras $(\mathrm{RG})$ pendant 12 semaines. Ensuite, les souris nourries par RG et les souris nourries par FG ont été divisées en 4groupes: RG-Exercice, RG-Sédentaire, FG-Exercice, FG-Sédentaire. Le groupe d'exercices a reçu de l'exercice sur un tapis roulant motorisé pendant 45minutes/jour, 5jours/semaine pendant 8semaines. Les souris ont été sacrifiées 24heures après la dernière séance d'exercice. Le muscle gastrocnémien et le tissu adipeux viscéral ont été excisés et congelés pour l'évaluation des taux d'ARNm de Pgc-1 $\alpha$ et de Fndc5 et des protéines.

Le niveau protéique de la PGC-1 $\alpha$ musculaire a diminué chez les souris RG c. FG et chez les souris obèses c. non obèses. De plus, les taux d'ARNm de Fndc5 ont été augmentés dans le tissu musculaire des groupes RG c. FG et chez les souris obèses c. non obèses. Dans le muscle squelettique du muscle gastrocnémien, les taux protéiques du FNDC5 étaient-ils significativement plus élevés chez les souris en regime-riche-gras que leurs homologues en regime-faible-gras, similaires à ceux chez les souris sédentaires.

Généralement, nous avons constaté que le régime-riche-gras augmentait les niveaux de transcription Fndc5 dans le muscle squelettique tandis que l'exercice avait un effet minime sur le niveau de transcription de Fndc5 lorsque l'entraînement en endurance augmentait la teneur en protéines du FNDC5. 
Mots clés : l'entrainement d'endurance; Fndc5; le régime riche en gras; Irisin; Obésité.

\begin{abstract}
Abbreviations:
ANOVA, two-way analysis of variance; BAT, Brown adipose tissue; BMI, Body mass index; DIO model, Diet-induced obesity model; EDTA, Ethylenediamine tetra-acetic acid; FA, fatty acids; Fndc5, Fibronectin type III domain containing 5; Gapdh, Glyceraldehyde 3-phosphate dehydrogenase; HF, High-fat; LF, Low-fat; Pgc-1 $\alpha$, Peroxisome proliferator-activated receptor (PPAR) $\gamma$ coactivator $1 \alpha$; RT q-PCR, Real-time quantitative PCR; SEM, standard error of the mean; Ucp1, Uncoupling protein 1; Vis. WAT, Visceral white adipose tissue; WAT, White adipose tissue;
\end{abstract}




\section{Introduction:}

Overweight and obesity are very dominant conditions in developed countries. While genetic factors contribute to the variation of adiposity, obesity results from some imbalance between energy intake and energy expenditure, mostly due to the high consumption of hyper-caloric food and/or diminished levels of physical activity. Both skeletal muscles and adipose tissues have been found to act as endocrine organs through the secretion of hormones called myokines and adipokines, respectively; and the crosstalk between them is vital for body weight and metabolism (Reinehr et al. 2015; Al-Daghri et al. 2016). Skeletal muscle is the major organ responsible for metabolic homoeostasis. Adaptive changes of the skeletal muscle in response to exercise include modifications in the production and secretion of myokines. Myokines not only act locally in the muscle through a paracrine/autocrine fashion, but also they are released to the blood as endocrine factors to adjust physiological processes in other metabolic tissues such as adipose tissue (Rodriguez et al. 2017). Adipose tissue consists of two different sections: white adipose tissue (WAT) and brown adipose tissue (BAT). WAT is involved in the adjustment of energy homeostasis through the storage of extra energy, while BAT exerts a thermogenic activity, producing heat by non-shivering thermogenesis, thereby regulating body's temperature (Beranger et al. 2013; Elsen et al. 2014). Therefore, browning of adipose tissue is postulated to increase insulin sensitivity and decrease weight gain (AlDaghri et al. 2016).

In 2012, Boström and colleagues found that exercise could increase the expression of the skeletal muscle Fndc5 (Fibronectin type III domain-containing protein 5), a membrane protein encoded via the Fndc5 gene. The Fndc5 protein is cleaved and secreted as a novel hormone/myokine called irisin (Bostrom et al. 2012); some beneficial impacts of chronic 
exercise could be mediated through this hormone. Downstream effects of Irisin include "browning" of the white adipose through increased uncoupling protein $1(U c p-1)$ levels, a specified mitochondrial protein which contributes to the transformation of the white adipose tissue (WAT) to the brown adipose tissue (BAT) via wasting energy in the form of heat (Bostrom et al. 2012; Wu et al. 2014). BAT has been shown to increase energy expenditure, thus serving a potential role as Fndc5/irisin in the treatment of obesity and obesity-related diseases such as type II diabetes. Furthermore, Fndc5 from muscle has numerous roles in energy metabolism, such as stimulating mitochondrial biogenesis and oxidative metabolism (Seale et al. 2007; Bostrom et al. 2012). In addition, Pgc-1 $\alpha$ increases $U c p-1$ expression in the white adipose tissue which elevates energy expenditure (Seale et al. 2007; Wu et al. 2014). Moreover, the exercise-induced expression of Fndc5/irisin in muscle has been shown to be dependent on the increased amount of Pgc-1 $\alpha$ (Bostrom et al. 2012; Brenmoehl et al. 2014; Norheim et al. 2014; Wu et al. 2014; Nygaard et al. 2015).

Several studies have assayed the effect of exercise training on the Pgc-1 $\alpha-F n d c 5 /$ irisin pathway. However, there are some controversies too. Subsequent to acute exercise, Fndc5/irisin levels are significantly raised making increased energy consumption in mice (Bostrom et al. 2012; Brenmoehl et al. 2014) and humans (Norheim et al. 2014; Nygaard et al. 2015). This increased energy consumption is suggested to be mediated by the increased browning of the white adipose tissue through Ucp-1 levels (Bostrom et al. 2012; Wu et al. 2014). Nevertheless, some studies have found the opposite effects of exercise on Fndc5/irisin. One study considering chronic adaptation in humans in response to resistance training reported no change in irisin levels (Ellefsen et al. 2014) while another one described an increase in human's irisin level as well as Fndc5 and $P g c-1 \alpha$ in response to both chronic and acute endurance training (Bang et al. 2014; Nygaard et al. 2015). Contradictory to this, another research elucidated that chronic endurance training increased both Pgc-1 $\alpha$ and Fndc5 
levels, whereas circulating irisin reached its peak only in response to acute exercise (Norheim et al. 2014). Further analysis is, therefore, required to assess the exact role of chronic exercise training on FNDC5/irisin.

One of the important aspects is the effect of other factors besides exercise on regulating serum/plasma irisin. There are a number of controversial results in the literature regarding the association between serum/plasma irisin and body mass index (BMI). Some studies have reported that irisin is positively correlated with BMI and fat mass (Huh et al. 2012; Stengel et al. 2013; Crujeiras et al. 2014b; Pardo et al. 2014; Park et al. 2014; Crujeiras et al. 2015). Conversely, a few studies have shown a reverse relationship between circulating irisin levels and obesity (Moreno-Navarrete et al. 2013; Sanchis-Gomar et al. 2014), or no correlation with BMI (Barja-Fernandez et al. 2016). Due to the potential preventive or compensatory role of the Pgc-1 $\alpha-F n d c 5 /$ irisin pathway in the improvement of obesity and obesity-related diseases, the effects of nutritional status, fat mass, bodyweight and endurance exercise on this pathway have been seriously examined. The results have suggested that irisin may play a compensatory role as an adipokine released in response to the deterioration of glucose/lipid metabolism (Roca-Rivada et al. 2013; Crujeiras et al. 2015; Huth et al. 2015). For instance, in both mice and human subjects, serum Fndc5/irisin is increased in response to hypocaloric diet and restriction-induced weight loss (Crujeiras et al. 2014a; Park et al. 2014; Seo et al. 2014; Wu et al. 2014; Huerta et al. 2015; Schlogl et al. 2015). High fat diet fed mice had a higher serum irisin level than their lean counterparts (Seo et al. 2014; Wu et al. 2014). These results have been confirmed in consumers with a high-calorie diet and increased fasting glucose levels exhibited enhanced serum irisin levels (Huerta et al. 2015; Schlogl et al. 2015). Also, human cell culture adipocytes have exhibited significantly developed levels of $P g c-1 \alpha$ in response to adipogenesis and increased adiposity levels to keep ATP homeostasis (Keuper et al. 2014). Additionally, plasma irisin levels are positively associated with fat mass 
(Stengel et al. 2013), as well as body mass index (Pardo et al. 2014). This upregulation of the $P g c-1 \alpha-F n d c 5 /$ irisin pathway is attended by the intense increase in the muscle Pgc-1 $\alpha$ mRNA (Srinivasa et al. 2016) and $U c p-1$ activity in the adipose tissue found in obese patients with insulin resistance (O'Rourke et al. 2011). Consistently, numerous studies have shown that calorie restriction/exercise intervention can cause a reduction in plasma irisin levels (Huh et al. 2012; Sharma et al. 2012; Crujeiras et al. 2014a). Considering that irisin may act as a regulatory adipokine, it can act as a therapeutic approach to ameliorate obesity-associated metabolic disturbances. Accordingly, the aim of this study was to determine the effects of a high-fat diet, background fat mass, chronic endurance training on the $P g c-1 \alpha-F n d c 5 /$ irisin pathway in the skeletal muscle and the visceral white adipose tissue.

\section{Materials/Subjects and Methods:}

\section{Ethics Issue}

All experiments with animals were carried out according to the policy of the Ethics Committee of the University of Isfahan and Royan Institute, which was compatible with Canadian Council on Animal Care guidelines.

\section{First Intervention (Long-term High-Fat Diet)}

As shown in Figure 1A, a protocol with two interventions was used for this study. Six-weekold male $\mathrm{C} 57 \mathrm{BL} / 6$ mice $(\mathrm{n}=48)$ with an estimated weight of $12-16 \mathrm{~g}$ were kept under normal light conditions (12 h light-dark cycle), the temperature of $23 \pm 1{ }^{\circ} \mathrm{C}$, and the moisture of $50 \pm 3 \%$ in cages. Animals were fed with the pellet rodent diet ad libitum and had free access to the water. Food intake was measured daily. Body weight was measured at weekly intervals. Mice were randomly assigned to one of the two diets for a period of 12 weeks: 1 . Low-fat diet (LF) $(10 \% \mathrm{kcals}$ from fat, $70 \% \mathrm{kcal}$ from carbohydrate, and $20 \% \mathrm{kcal}$ from protein) 2. High-fat diet (HF) (45\% kcals from fat, 35\% kcal from carbohydrate, the $20 \% \mathrm{kcal}$ 
from protein). Mice with high-fat diet displayed extreme states of obesity, and they were examined based on the effects of the primary diet and the background fat mass vs the low-fat diet fed mice (lean control). These diet-induced obesity (DIO) models could be generally used to induce visceral adipose tissue accumulation, obesity, and the associated metabolic disorders in the experimental animals (Bagnol et al. 2012). All animals had free access to water and food during the whole length of the protocol.

\section{Second Intervention (Exercise and Diet)}

After twelve weeks (at the beginning of the week 13), the LF animals (non-obese mice) were randomly assigned to 4 groups: 1. high-fat diet, exercise-trained (HF-E), 2. high-fat diet, sedentary (HF-S), 3. low-fat, exercise-trained (LF-E), and 4. low-fat diet, sedentary (LF-S). Also, HF animals (obese mice) were randomly divided to 4 groups: 1 . high-fat diet, exercisetrained (HF-E), 2. high-fat diet, sedentary (HF-S), 3. low-fat diet, exercise-trained (LF-E), and 4. low-fat diet, sedentary (LF-S). The training program began with the adaptation of mice to the apparatus for 7 days by placing them on the motor-driven treadmill. The training protocol was as follows: first, mice were exercised on the treadmill at $17 \mathrm{~m} / \mathrm{min}$ for $15 \mathrm{~min}$. One week after the beginning of the experiment, the time and speed of running were increased steadily to $45 \mathrm{~min} /$ day at $17 \mathrm{~m} / \mathrm{min}$. After this step, the experimental group received some progressive exercise. They were again made to run on a treadmill for $45 \mathrm{~min} / \mathrm{day}, 5$ days/week, one session/day. During the first and second weeks of exercises, the speed was set to $17 \mathrm{~m} / \mathrm{min}$, while for the third and fourth, fifth and sixth, and seventh and eighth weeks; it was adjusted to 19,21 and $23 \mathrm{~m} / \mathrm{min}$, respectively. The angle of inclination was $0 \%$ gradient during the whole period of the study. This condition corresponded to the moderate intensity of about $65 \%$ of the maximal oxygen consumption (Powers et al. 1993). Untrained mice were not exposed to exercise session and stayed in their cages during the protocol. 


\section{Muscle, Visceral White Adipose Tissue, and Blood collection}

By following the 8-week intervention, mice were weighed on the day of sacrifice. Finally, twenty-four hours after the last exercise session (eighth week), all mice were sacrificed. Blood samples were taken from the right ventricle of each mouse and immediately transferred to EDTA containing tubes. Then samples were centrifuged immediately at $3 \times 10^{3}$ $\mathrm{g}$ for 15 minutes to separate the plasma. The obtained plasma was stored at $-80{ }^{\circ} \mathrm{C}$ for future measurements. Skeletal muscle (Gastrocnemius), Visceral WAT (around intestinal digestive organs) and Brown adipose tissue (BAT interscapular) were dissected and weighed; they were calculated as the ratio of tissue and body weights.

\section{Measurement of Plasma Irisin Levels}

Plasma concentrations of irisin were measured in duplicate using a commercially available enzyme immunoassay kit (Catalog no: EK-067-29, Phoenix Pharmaceuticals, USA) with a detectable range of 0.1 to $1000 \mathrm{ng} / \mathrm{mL}$ ). The antibody used with this particular kit had been validated with western blotting (Wen et al. 2013) and mass spectrometry (Lee et al. 2014; Zhang et al. 2014).

\section{RT-qPCR Analyses}

The total RNA of the skeletal muscle and the visceral WAT was isolated using the TRIzol reagent as described by the manufacturer (Thermo Scientific). The concentration and purity of RNA were assessed using NanoDrop1000 spectrophotometer by reading the absorbance at $230 \mathrm{~nm}, 260 \mathrm{~nm}$ and $280 \mathrm{~nm}$. One $\mu \mathrm{g}$ of the total RNA was treated with DNaseI (Thermo Scientific) in order to eliminate the residual genomic DNA, and one point five micrograms of the total RNA from each sample was used as a template for cDNA production using the NZY First-strand cDNA Synthesis Kit (TaKaRa, Japan), which included a combination of random hexamer primer. Real-time quantitative PCR (RT-qPCR) was carried out using the SYBR 
Green PCR Master Mix (TaKaRa, Japan), on a Step One Plus thermocycler (ABI Applied Biosystems, USA) with the respective primer pairs, as shown in the supplementary table S1. Each sample was assayed in a $10 \mu \mathrm{L}$ reaction in triplicate. All reactions were performed under the same conditions of PCR, which included $95{ }^{\circ} \mathrm{C}$ for $30 \mathrm{~s}, 40$ cycles of $95{ }^{\circ} \mathrm{C}$ for $5 \mathrm{~s}$ and $72{ }^{\circ} \mathrm{C}$ for $30 \mathrm{~s}$. The data were analyzed using glyceraldehyde 3-phosphate dehydrogenase $\left(\right.$ Gapdh) as the internal control calculation based on the cycle threshold $\left(2^{-\Delta \Delta \mathrm{CT}}\right)$ method as recommended by ABI Applied Biosystems.

\section{Protein extraction and Western blotting analyses}

Tissues were lysed using TRI reagent (Thermo Scientific, 15596-018), according to the manufacturer's protocol. Equal amounts of each protein sample $(30 \mu \mathrm{g})$ were separated by SDS- PAGE and transferred to PVDF membranes (Bio Rad, 162-0176). After blocking the membranes with 10\% skim milk (Millipore, 115363), the membranes were incubated with different primary antibodies for $2 \mathrm{~h}$ at room temperature. Primary antibodies were as follows: rabbit anti-FNDC5 antibody (1:2000, Abcam, AB174833), mouse anti-PGC-1 $\alpha$ antibody (1:200, Merck, ST1202), mouse anti GAPDH antibody (1:5000, Santa Cruz) and mouse antimitochondria which recognized a $60 \mathrm{kD}$ non-glcosylated protein component of mitochondria (1:400, Abcam, AB3298). Then, the membranes were incubated for $1 \mathrm{~h}$ at room temperature with an appropriate secondary antibody: horseradish peroxidase (HRP)-conjugated goat antimouse IgG (1:5000, Dako, P0447), or HRP-conjugated goat anti-rabbit IgG (1:16000, Santa Cruz, SC2301). HRP-conjugated IgG bound to each protein band was visualized by an Amersham ECL Advance Western Blotting Detection Kit (GE Healthcare).

\section{Statistical Analysis}

Values are presented as the mean \pm standard error of the mean (SEM). The effect of diet and exercise was analyzed using the two-way analysis of variance (ANOVA). For factors 
showing correlation (skeletal muscle Fndc5 and fat mass), partial correlation coefficients were calculated using the skeletal muscle $P g c-1 \alpha$ as a control variable. All statistical analyses were accomplished using SPSS (Version 19), and differences at $p<0.05$ were considered to be significant in all analyses.

\section{Results}

The effects of diet, exercise and obesity on body weight and fat mass

As shown in Figure1A, a protocol with two interventions was used for this study. Animal weight is shown in Figure 1. At the beginning of the first intervention (12-week HF and LF), there was no difference in the body weight of the mice. However, after five weeks of intervention, a significant difference in the body weight was observed between LF fed and HF fed mice (Figure 1B). After the first intervention (13th week), HF fed mice weighed significantly more than the LF fed ones (Figure 1B, final weight of LF fed mice: $25.8 \pm 0.9 \mathrm{~g}$, final weight of HF fed mice: $36.87 \pm 1.2 \mathrm{~g}, p<0.001$ ). Figure $1 \mathrm{C}$ shows that the body weight gain of the obese mice in the HF-S group was significantly more than that in the HF-E one $(p<0.05)$; Furthermore, the gain of body weight in the LF-S group was non-significantly more than that in the LF-E one $(p>0.05)$. Figure 1D shows that the body weight gain of the nonobese mice in the HF-S group was also more than that in the HF-E one, significantly $(p<0.05)$, and the gain of body weight in the LF-S group was non-significantly more than that in the LF-E one $(p>0.05)$.

We also evaluated \%WAT/body weight ratio in obese and non-obese mice using the two-way ANOVA. The obtained results revealed a decrease in the fat mass ratio in exercise groups vs non-exercised animals (Figure $2 \mathrm{~A}$ and $2 \mathrm{C}, p<0.05$, exercise effect). There was an increase in the fat mass ratio in the mice fed with HF, as compared to those fed with LF (Figure 2A and $2 \mathrm{C}, p<0.001$, diet effect). There were no main effects for obesity (First intervention) (Figure 
$2 \mathrm{~A}$ and $2 \mathrm{C}, p>0.05$, obesity effect), while exercise and diet had a significant effect on the fat mass ratio (Second intervention, $p<0.05$ ). Meanwhile, there was no significant effect for exercise and obesity ( $p>0.05)$, diet and obesity ( $p>0.05)$, and obesity (First intervention), and exercise and diet (Second intervention) $(p>0.05)$ interactions (Table 1).

The effect of exercise on \%BAT/body weight ratio was assessed, showing that exercised animals had higher BAT/body weight ratio, as compared to their non-exercised counterparts (Figure $2 \mathrm{~B}$ and $2 \mathrm{D}, p<0.001$, exercise effect). There was a main effect on the BAT/body weight ratio for diet where HF fed mice had higher BAT/body weight ratio in comparison to their LF fed counterparts (Figure $2 \mathrm{~B}$ and $2 \mathrm{D}, p<0.05$, diet effect). Also, there was a main effect for obesity, with the obese mice having a higher BAT/body weight ratio, as compared to their non-obese counterparts (Figure $2 \mathrm{~B}$ and 2D, $p<0.001$, obesity effect) (Table 1). Interestingly, there was no significant effect for exercise and diet $(p>0.05)$, exercise and obesity $(p>0.05)$, diet and obesity $(p>0.05)$, and exercise and diet and obesity $(p>0.05)$ interactions (Table 1).

The Effects of diet, exercise and obesity on visceral (vis.) WAT Fndc5 and Pgc-1 $\alpha \mathrm{mRNA}$

In the vis. WAT, Pgc-1 $\alpha$ mRNA levels were not significantly different among exercised and non-exercised groups (Figure $3 \mathrm{~A}$ and $3 \mathrm{C}, p>0.05$, exercise effect) and there was no significant difference between HF fed mice and LF fed ones (Figure 3A and 3C, $p>0.05$, diet effect). Pgc-1 $\alpha$ transcript levels were significantly lower in the vis. WAT of the obese mice, as compared to their non-obese counterparts (Figure $3 \mathrm{~A}$ and $3 \mathrm{C}, p<0.05$, obesity effect), but there was no significant effect regarding exercise and diet $(p>0.05)$, exercise and obesity $(p>0.05)$, and diet and obesity $(p>0.05)$ interactions (Table 1). Interestingly, there was significantly interactions between exercise and diet, and obesity $(p<0.01)$ (Table 1). 
Fndc5 mRNA expression levels were decreased in the vis. white adipose tissue of the obese mice, as compared to their non-obese counterparts (Figure $3 \mathrm{~B}$ and $3 \mathrm{D}, p<0.01$, obesity effect), but not significant difference was found between exercised and non-exercised groups (Figure 3B and 3D, $p>0.05$, exercise effect). Also, there were no main effects for diet (Figure $3 \mathrm{~B}$ and $3 \mathrm{D}, p>0.05)$. There was no significant effect regarding exercise and diet $(p>0.05)$, exercise and obesity $(p>0.05)$, and diet and obesity $(p>0.05)$ interactions (Table 1$)$. Interestingly, there were significant interactions between exercise and diet and obesity $(p<0.05)$ (Table 1).

The effects of diet, exercise and obesity on skeletal muscle Pgc-1 $\alpha m R N A$ and protein

In the gastrocnemius skeletal muscle, RNA levels of $P g c-1 \alpha$ were not significantly modified among exercised and non-exercised groups (Figure 4A and 4C, $p>0.05$, exercise effect). Pgc$1 \alpha$ transcript levels were significantly lower in the high-fat fed mice, as compared to their low-fat fed counterparts (Figure 4A and 4C, $p<0.001$, diet effect), and they were significantly lower in obese vs non-obese mice (Figure $4 \mathrm{~A}$ and $4 \mathrm{C}, p<0.001$, obesity effect). There was also a significant effect regarding $\operatorname{diet}(p<0.001)$, exercise and obesity $(p<0.05)$, and exercise and diet and obesity $(p<0.001)$ interactions, but there were no interactions between diet and obesity $(p>0.05)$ (Table 1$)$.

In the gastrocnemius skeletal muscle, protein levels of PGC-1 $\alpha$ were significantly higher in the low-fat fed mice, as compared to their high-fat fed counterparts (Figure 4B and 4D, $p<0.001$, diet effect), and these levels were significantly higher in non-obese vs obese mice (Figure $4 \mathrm{~B}$ and 4D, $p<0.001$, obesity effect). Also, protein levels of PGC-1 $\alpha$ were significantly higher in the sedentary mice, as compared to exercised ones (Figure 4B and 4D, $p<0.001$, exercise effect). There was also a significant effect for exercise and $\operatorname{diet}(p<0.001)$, 
exercise and obesity $(p<0.001)$, and diet and obesity $(p<0.001)$ interactions but there were no interactions between exercise and diet and obesity $(p>0.05)$ (Table 1$)$.

The effects of diet, exercise and obesity on skeletal muscle Fndc5 mRNA and protein

RNA levels of Fndc5 were increased in the muscle tissue of the mice fed with HF vs counter parts with LF (Figure 5A and 5C, $p<0.001$, diet effect), and they were increased in the muscle tissue of the obese mice, as compared to their non-obese counterparts (Figure 5A and 5C, $p<0.05$, obesity effect), but there were no main effects for exercise (Figure $5 \mathrm{~A}$ and $5 \mathrm{C}$, $p>0.05$, exercise effect); there were no interactions between exercise and obesity either $(p>0.05)$. Meanwhile, there was a significant effect regarding exercise and diet $(p<0.05)$, diet and obesity $(p<0.01)$, and exercise and diet and obesity $(p<0.05)$ interactions (Table 1$)$.

Interestingly, Fndc5 mRNA expression levels in the muscle tissue were significantly associated with \%WAT/body weight. Partial correlation coefficients were also calculated using the skeletal muscle $P g c-1 \alpha$ as a control variable (Supplementary figure S1A, $\mathrm{r}=0.75, p<0.001)$. But Fndc5 mRNA expression levels in the vis. WAT tissue were not significantly correlated with \%WAT/body weight (Supplementary figure S1B, r=-0.28, $p>0.05)$.

In the gastrocnemius skeletal muscle, protein levels of FNDC5 were significantly higher in the high-fat fed mice, as compared to their low-fat fed counterparts (Figure 5B and 5D, $p<0.001$, diet effect), and these were significantly higher in exercised vs sedentary mice (Figure 5B and 5D, $p<0.001$, exercise effect). FNDC5 was not significantly modified among obese and non-obese groups (Figure 5B and 5D, $p>0.05$, obesity effect). There was also a significant effect for exercise and diet $(p<0.001)$, exercise and obesity $(p<0.001)$, and exercise and diet and obesity $(p<0.05)$ interactions but there were no interactions between diet and obesity $(p>0.05)$ (Table 1$)$. 
The effects of diet, exercise and obesity on mitochondrial protein of skeletal muscle

Protein levels of mitochondria were decreased in the muscle tissue of the mice fed with HF vs counter parts with LF (Figure $6 \mathrm{~A}$ and $6 \mathrm{~B}, p<0.001$, diet effect), and they were decreased in the muscle tissue of the obese mice, as compared to their non-obese counterparts (Figure 6A and $6 \mathrm{~B}, p<0.001$, obesity effect), and they were decreased in the muscle tissue of the exercised mice, as compared to their sedentary mice (Figure $6 \mathrm{~A}$ and $6 \mathrm{~B}, p<0.001$, exercise effect). Also, there was a significant effect regarding exercise and diet $(p<0.001)$, diet and obesity $(p<0.01)$, exercise and obesity $(p<0.001)$ and exercise and diet and obesity $(p<0.001)$ interactions (Table 1).

The effects of diet, exercise and obesity on skeletal muscle Ucp1 mRNA

RNA levels of Ucpl were increased in the muscle tissue of the mice fed with HF vs counter parts with LF (Figure 7A and 7B, $p<0.001$, diet effect), and they were increased in the muscle tissue of the obese mice, as compared to their non-obese counterparts (Figure 7A and 7B, $p<0.001$, obesity effect) and they were increased in the muscle tissue of the exercised mice, as compared to sedentary mice (Figure $7 \mathrm{~A}$ and $7 \mathrm{~B}, p<0.05$, exercise effect). Also, there was a significant effect regarding diet and obesity $(p<0.001)$ interactions but there were no interactions between exercise and diet $(p>0.05)$, exercise and obesity $(p>0.05)$, and exercise and diet and obesity $(p<0.05)$ interactions (Table 1$)$.

The effects of diet, exercise and obesity on plasma irisin

Plasma irisin levels were assessed by ELISA. The results of circulating irisin levels are shown in Figure 8. The highest level of irisin was observed in the obese mice, especially in the HF-S group $(2.74 \pm 0.12 \mathrm{ng} / \mathrm{mL})$. In the obese mice, plasma irisin levels were significantly higher, as compared to their non-obese counterparts (Figure $8 \mathrm{~A}$ and $8 \mathrm{~B}, p<0.05$, obesity effect); interestingly there was no main effect for exercise $(p>0.05)$ and $\operatorname{diet}(p>0.05)$ (Figure 
8A and 8B) (Table 1). Also, plasma irisin was not significantly correlated with Fndc5 mRNA expression levels in the skeletal muscle (Supplementary figure $\mathrm{S} 1 \mathrm{C}, \mathrm{r}=0.28, p>0.05$ ).

\section{Discussion:}

In this study, we delineated the increased transcript levels of Fndc5 in the skeletal muscle of the obese mice, as compared to the non-obese and high-fat fed mice, and investigated them in low-fat fed mice for comparison purposes. Here, for the first time, we reported the simultaneous effects of obesity, high fat diet and exercise on the visceral adipose tissue, the skeletal muscle Fndc5 mRNA, its related Pgc-1 $\alpha$ mRNAs, the muscle FNDC5 protein, and plasma irisin in male C57BL/6 mice. Nevertheless, the role of the PGC-1 $\alpha$ - FNDC5/irisin pathway in the regulation of energy metabolism still remains unclear.

Irisin has been reported to be initially a $P g c-1 \alpha$-dependent exercise-inducible myokine that can stimulate the browning of the adipose tissue through the increased thermogenesis (Bostrom et al. 2012). This hormone can have useful effects on metabolism by inducing the browning of subcutaneous white adipocytes and contributing to the organ crosstalk, which is crucial to maintain metabolic homeostasis (Al-Daghri et al. 2014; Sesti et al. 2014). Interestingly, our study indicated that after 8 weeks of chronic endurance training, the exercised mice showed no significant increase in the relative expression of skeletal muscle Fndc5 mRNA, as compared to the sedentary mice. We propose that this might be due to the temporary effect of exercise on Fndc5 mRNA in the gastrocnemius muscle. In agreement with this, numerous studies (Bostrom et al. 2012; Brenmoehl et al. 2014; Norheim et al. 2014; Nygaard et al. 2015) including Nygaard et al. have shown that skeletal muscle Fndc5 mRNA levels reach their peak a few hours after an acute session of endurance exercise and return to the baseline level after 24 hours (Nygaard et al. 2015). However, in our study, we evaluated the effect of the 8-week exercise on the transcript levels of Fndc5 mRNA in mice. 
Thus, we observed an increasing trend of Fndc5 mRNA levels in the skeletal muscle of obese, sedentary and high-fat fed mice in comparison with non-obese, exercised and low-fat fed mice, respectively. This can suggest that in sedentary high-fat diet fed mice, there is a demand for more energy expenditure to reciprocate uncommon metabolic conditions. This notion is supported by several studies indicating that diet-induced obesity upregulates Fndc5 RNA levels (Huh et al. 2012; Roca-Rivada et al. 2013; Stengel et al. 2013; Keuper et al. 2014; Wu et al. 2014; Schlogl et al. 2015); for example, Seo et al. showed that sedentary rats fed by a high fat diet had higher skeletal muscle Fndc5 transcript levels than their high-fat, exercised counterparts (Seo et al. 2014). Thus, the increased expression of Fndc5 mRNA in the skeletal muscle of sedentary and high-fat fed mice vs exercised and high-fat fed mice may point to the reparative role of $F n d c 5 /$ irisin as a myokine acting against the improvement of insulin resistance in the stages of pre-diabetes and obesity (Filipowicz et al. 2008; Sawada et al. 2014).

We found that both protein and mRNA levels of FNDC5 were higher in the high-fat fed mice, as compared to the low-fat fed ones. Interestingly, we observed that the protein level of FNDC5 in the skeletal muscle was higher in the exercised high-fat fed mice, in contrast to the sedentary high-fat fed ones. Presumably, this incompatibility between mRNA and protein levels of FNDC5 in the HF-S mice is related to the activity of some regulators which affect protein translation, such as microRNAs. Several studies have shown that microRNAs act at the levels of stability, post-transcriptional, and translation of target proteins (Bartel 2004; Filipowicz et al. 2008).

Interestingly, we did not detect any significant increases in the expression of $P g c-1 \alpha$ mRNA levels in the skeletal muscle of the exercised mice, as compared to the sedentary groups. Primarily, Bostrom et al. have reported $P g c-1 \alpha$ drives the release of $F n d c 5 /$ irisin from muscle 
in response to the acute sessions of endurance exercise (Bostrom et al. 2012). Other studies have also reported that the expression of $P g c-1 \alpha$ is raised after chronic exercise training (Roca-Rivada et al. 2013; Bang et al. 2014). However, our results indicated that perhaps $P g c-1 \alpha$ mRNA increases had transient effects similar to those of Fndc5 mRNA levels, in response to endurance training. We suggest that acute exercise in the skeletal muscle may increase $P g c-1 \alpha$ mRNA and this is followed by an increase in Fndc5/irisin; however, these effects are transient as Fndc5/irisin levels return to baseline soon after a few hours of postexercise. Interestingly, despite this vigorous increase in the skeletal muscle Fndc5 mRNA in high-fat diet, there was no increase in $P g c-1 \alpha$ transcripts in skeletal muscle following the high-fat diet. Previous studies have shown that a high-fat diet reduces $P g c-1 \alpha$ expression in the skeletal muscle (Sparks et al. 2005; Crunkhorn et al. 2007). Crunkhorn et al. reported long chain saturated fatty acids (FA) including palmitate and stearate could potently decrease both Pgc-1 $\alpha$ expression and short chain, unsaturated, omega-3; while non-metabolizing FAs could have no effect (Crunkhorn et al. 2007). Therefore, it is possible that free FAs in plasma can decrease the expression of $P g c-1 \alpha$ in the gastrocnemius muscle of the high-fat diet fed mice.

On the other hand, we did not observe any relationship between Fndc5 mRNA and the circulated irisin, possibly due to the fact that the regulation of irisin synthesis from Fndc5 mRNA may be a more important step in regulating the irisin concentration in blood. Maximal concentrations of plasma irisin occurred $1 \mathrm{~h}$ after training, thereby supporting the idea that irisin is an exercise-inducible myokine (Huh et al. 2012; Huh et al. 2014), and its increase is transient (Huh et al. 2014; Kraemer et al. 2014; Norheim et al. 2014). Previous studies have displayed the increased circulating irisin instantly after endurance training (Huh et al. 2012; Kraemer et al. 2014). Another study showed that the circulating irisin level was increased during 90 minutes of treadmill exercise at $60 \%$ of VO2max, but at the end of the exercise, 
irisin levels were rebounded to the baseline (Kraemer et al. 2014). Overall, it is more likely that irisin concentration in blood reaches it peak within the first two hours at the beginning of the exercise. The observed increases in plasma irisin concentrations were not correlated with the increases in the skeletal muscle Fndc 5 expression, as measured in $4 \mathrm{~h}$ post-exercise. This suggests that regulation of irisin in blood does not depend on the transcriptional regulation of Fndc5 mRNA in muscle, which is similar to that in human (Timmons et al. 2012; Pekkala et al. 2013).

Recently, the compensatory adipokine role of Fndc5/irisin from adipose has been reported, which is secreted during uncommon metabolic disturbances such as obesity and insulin resistance (Roca-Rivada et al. 2013; Keuper et al. 2014; Crujeiras et al. 2015). However, we observed no significant difference in Fndc5 mRNA levels among groups when analyzed according to RNA levels in the adipose tissue.

Finally, we characterized a correlation in muscle Fndc5 transcript levels with fat mass in the obese mice. This supported our notion that perhaps the transcript levels of muscle Fndc5 mRNA were intensified in (obese, HF-E) and (obese, HF-S) groups to allow for greater energy expenditure in mice, thereby representing a demand for more energy expenditure due to the high-fat diet. In human, there is a controversy regarding the relation of circulating irisin levels with BMI (Huh et al. 2012; Timmons et al. 2012; Moreno-Navarrete et al. 2013; Stengel et al. 2013). The most recent studies have detected a positive correlation between circulating irisin and BMI (Pardo et al. 2014), revealing the physiological response of the anti-obesity effect of irisin (Bostrom et al. 2012).

Taken together, in this study, Fndc5 mRNA levels in the skeletal muscle were positively linked to fat mass, but Fndc5 mRNA levels in the visceral adipose tissue were not correlated with fat mas. This finding showed that irisin is mostly produced by adipose tissue and 
skeletal muscle, but circulated irisin could be increased instantly after endurance training; at the end of exercise, irisin levels could be rebounded to the baseline. Additional studies including the identification of the receptor and the signaling pathway of irisin are required for the clarification of the cross talk between the adipose tissue derived irisin and irisin from the skeletal muscle in both mice and human, especially in the obesity state. Our results suggest that the muscle Fndc5 may play a role in uncommon metabolic states as a compensatory mechanism to persist the development of obesity. Considering the central role of PGC-1 $\alpha$ in regulation of mitochondrial function, using antimitochondrial antibody indicated the similar pattern of mitochondrial protein with PGC-1 $\alpha$. However, assessment of Ucpl transcript levels showed the same pattern as Fndc5 mRNA. Therefore, it could be suggested an alternative pathway may control Fndc5- Ucpl levels besides of PGC-1 $\alpha$ which should be elucidated in further studies.

\section{Author Contributions:}

Fatemeh Kazeminasab: Experimental design, collection and/or assembly of data, data analysis, interpretation and manuscript writing

Mohammad Marandi: Conception, design, data analysis, interpretation, manuscript writing and final approval of manuscript

Kamran Ghaedi: Conception, design, data analysis, interpretation, manuscript writing and final approval of manuscript

Zahra Safaeinejad: Preparation of revised manuscript, experimental design, data analysis Fahimeh Esfarjani: Conception, design, data analysis, interpretation and final approval of manuscript 
Mohammad Hossein Nasr-Esfahani: Conception, design, data analysis, interpretation, manuscript writing and final approval of manuscript

\section{Ethical approval statement:}

Approval for this study was obtained from the Institutional Review Board of Royan Institute (Tehran, Iran).

\section{Conflict of Interest:}

None of the authors has any conflicts of interest to disclose and all authors support submission to this journal.

\section{Acknowledgments:}

This study was funded partly by a grant-in-aid of University of Isfahan and Royan Institute in the support of Fatemeh Kazeminasab for obtaining her Ph.D. degree from University of Isfahan. The authors are also thankful to other members of Royan Institute for their excellent technical assistance and advice.

\section{References:}

Al-Daghri, N.M., Alkharfy, K.M., Rahman, S., Amer, O.E., Vinodson, B., Sabico, S., et al. 2014. Irisin as a predictor of glucose metabolism in children: sexually dimorphic effects. Eur. J. Clin. Invest. 44: 119-24. doi: 10.1111/eci.12196. PMID: 24188288.

Al-Daghri, N.M., Mohammed, A.K., Al-Attas, O.S., Amer, O.E., Clerici, M., Alenad, A., et al. 2016. SNPs in FNDC5 (irisin) are associated with obesity and modulation of glucose and lipid metabolism in Saudi subjects. Lipids Health Dis. 15: 54. doi: 10.1186/s12944-0160224-5. PMID: 26968837. 
Bagnol, D., Al-Shamma, H.A., Behan, D., Whelan, K., and Grottick, A.J. 2012. Diet-induced models of obesity (DIO) in rodents. Curr. Protoc. Neurosci. Chapter 9: Unit 938 1-13. doi: 10.1002/0471142301.ns0938s59. PMID: 22470151.

Bang, H.S., Seo, D.Y., Chung, Y.M., Oh, K.M., Park, J.J., Arturo, F., et al. 2014. Ursolic Acid-induced elevation of serum irisin augments muscle strength during resistance training in men. Korean J. Physiol. Pharmacol. 18: 441-6. doi: 10.4196/kjpp.2014.18.5.441. PMID: 25352765 .

Barja-Fernandez, S., Folgueira, C., Castelao, C., Al-Massadi, O., Bravo, S.B., GarciaCaballero, T., et al. 2016. FNDC5 is produced in the stomach and associated to body composition. Sci. Rep. 6: 23067. doi: 10.1038/srep23067. PMID: 26961074.

Bartel, D.P. 2004. MicroRNAs: genomics, biogenesis, mechanism, and function. Cell, 116: 281-97. PMID: 14744438.

Beranger, G.E., Karbiener, M., Barquissau, V., Pisani, D.F., Scheideler, M., Langin, D., et al. 2013. In vitro brown and "brite"/"beige" adipogenesis: human cellular models and molecular aspects. Biochim. Biophys. Acta, 1831: 905-14. doi: 10.1016/j.bbalip.2012.11.001. PMID: 23146742.

Bostrom, P., Wu, J., Jedrychowski, M.P., Korde, A., Ye, L., Lo, J.C., et al. 2012. A PGC1alpha-dependent myokine that drives brown-fat-like development of white fat and thermogenesis. Nature, 481: 463-8. doi: 10.1038/nature10777. PMID: 22237023.

Brenmoehl, J., Albrecht, E., Komolka, K., Schering, L., Langhammer, M., Hoeflich, A., et al. 2014. Irisin is elevated in skeletal muscle and serum of mice immediately after acute exercise. Int. J. Biol. Sci. 10: 338-49. doi: 10.7150/ijbs.7972. PMID: 24644429.

Crujeiras, A.B., Pardo, M., Arturo, R.R., Navas-Carretero, S., Zulet, M.A., Martinez, J.A., et al. 2014a. Longitudinal variation of circulating irisin after an energy restriction-induced 
weight loss and following weight regain in obese men and women. Am. J. Hum. Biol. 26: 198-207. doi: 10.1002/ajhb.22493. PMID: 24375850.

Crujeiras, A.B., Pardo, M., and Casanueva, F.F. 2015. Irisin: 'fat' or artefact. Clin. Endocrinol. (Oxf.) 82: 467-74. doi: 10.1111/cen.12627. PMID: 25287317.

Crujeiras, A.B., Zulet, M.A., Lopez-Legarrea, P., de la Iglesia, R., Pardo, M., Carreira, M.C., et al. 2014b. Association between circulating irisin levels and the promotion of insulin resistance during the weight maintenance period after a dietary weight-lowering program in obese patients. Metabolism, 63: 520-31. doi: 10.1016/j.metabol.2013.12.007. PMID: 24439241.

Crunkhorn, S., Dearie, F., Mantzoros, C., Gami, H., da Silva, W.S., Espinoza, D., et al. 2007. Peroxisome proliferator activator receptor gamma coactivator-1 expression is reduced in obesity: potential pathogenic role of saturated fatty acids and p38 mitogen-activated protein kinase activation. J. Biol. Chem. 282: 15439-50. doi: 10.1074/jbc.M611214200. PMID: 17416903.

Ellefsen, S., Vikmoen, O., Slettalokken, G., Whist, J.E., Nygaard, H., Hollan, I., et al. 2014. Irisin and FNDC5: effects of 12-week strength training, and relations to muscle phenotype and body mass composition in untrained women. Eur. J. Appl. Physiol. 114: 1875-88. doi: 10.1007/s00421-014-2922-x. PMID: 24906447.

Elsen, M., Raschke, S., and Eckel, J. 2014. Browning of white fat: does irisin play a role in humans? J. Endocrinol. 222: R25-38. doi: 10.1530/JOE-14-0189. PMID: 24781257.

Filipowicz, W., Bhattacharyya, S.N., and Sonenberg, N. 2008. Mechanisms of posttranscriptional regulation by microRNAs: are the answers in sight? Nat. Rev. Genet. 9: 10214. doi: 10.1038/nrg2290. PMID: 18197166.

Huerta, A.E., Prieto-Hontoria, P.L., Fernandez-Galilea, M., Sainz, N., Cuervo, M., Martinez, J.A., et al. 2015. Circulating irisin and glucose metabolism in overweight/obese women: 
effects of alpha-lipoic acid and eicosapentaenoic acid. J. Physiol. Biochem. 71: 547-58. doi: 10.1007/s13105-015-0400-5. PMID: 25820474.

Huh, J.Y., Mougios, V., Kabasakalis, A., Fatouros, I., Siopi, A., Douroudos, I.I., et al. 2014. Exercise-induced irisin secretion is independent of age or fitness level and increased irisin may directly modulate muscle metabolism through AMPK activation. J. Clin. Endocrinol. Metab. 99: E2154-61. doi: 10.1210/jc.2014-1437. PMID: 25119310.

Huh, J.Y., Panagiotou, G., Mougios, V., Brinkoetter, M., Vamvini, M.T., Schneider, B.E., et al. 2012. FNDC5 and irisin in humans: I. Predictors of circulating concentrations in serum and plasma and II. mRNA expression and circulating concentrations in response to weight loss and exercise. Metabolism, 61: 1725-38. doi: 10.1016/j.metabol.2012.09.002. PMID: 23018146.

Huth, C., Dubois, M.J., Marette, A., Tremblay, A., Weisnagel, S.J., Lacaille, M., et al. 2015. Irisin is more strongly predicted by muscle oxidative potential than adiposity in non-diabetic men. J. Physiol. Biochem. 71: 559-68. doi: 10.1007/s13105-015-0402-3. PMID: 25820475.

Keuper, M., Jastroch, M., Yi, C.X., Fischer-Posovszky, P., Wabitsch, M., Tschop, M.H., et al. 2014. Spare mitochondrial respiratory capacity permits human adipocytes to maintain ATP homeostasis under hypoglycemic conditions. FASEB J. 28: 761-70. doi: 10.1096/fj.13238725. PMID: 24200885.

Kraemer, R.R., Shockett, P., Webb, N.D., Shah, U., and Castracane, V.D. 2014. A transient elevated irisin blood concentration in response to prolonged, moderate aerobic exercise in young men and women. Horm. Metab. Res. 46: 150-4. doi: 10.1055/s-0033-1355381. PMID: 24062088.

Lee, P., Linderman, J.D., Smith, S., Brychta, R.J., Wang, J., Idelson, C., et al. 2014. Irisin and FGF21 are cold-induced endocrine activators of brown fat function in humans. Cell. Metab. 19: 302-9. doi: 10.1016/j.cmet.2013.12.017. PMID: 24506871. 
Moreno-Navarrete, J.M., Ortega, F., Serrano, M., Guerra, E., Pardo, G., Tinahones, F., et al. 2013. Irisin is expressed and produced by human muscle and adipose tissue in association with obesity and insulin resistance. J. Clin. Endocrinol. Metab. 98: E769-78. doi: 10.1210/jc.2012-2749. PMID: 23436919.

Norheim, F., Langleite, T.M., Hjorth, M., Holen, T., Kielland, A., Stadheim, H.K., et al. 2014. The effects of acute and chronic exercise on PGC-1alpha, irisin and browning of subcutaneous adipose tissue in humans. FEBS J. 281: 739-49. doi: 10.1111/febs.12619. PMID: 24237962.

Nygaard, H., Slettalokken, G., Vegge, G., Hollan, I., Whist, J.E., Strand, T., et al. 2015. Irisin in blood increases transiently after single sessions of intense endurance exercise and heavy strength training. PLoS One, 10: e0121367. doi: 10.1371/journal.pone.0121367. PMID: 25781950.

O'Rourke, R.W., White, A.E., Metcalf, M.D., Olivas, A.S., Mitra, P., Larison, W.G., et al. 2011. Hypoxia-induced inflammatory cytokine secretion in human adipose tissue stromovascular cells. Diabetologia, 54: 1480-90. doi: 10.1007/s00125-011-2103-y. PMID: 21400042.

Pardo, M., Crujeiras, A.B., Amil, M., Aguera, Z., Jimenez-Murcia, S., Banos, R., et al. 2014. Association of irisin with fat mass, resting energy expenditure, and daily activity in conditions of extreme body mass index. Int. J. Endocrinol. 2014: 857270. doi: 10.1155/2014/857270. PMID: 24864142.

Park, K.H., Zaichenko, L., Peter, P., Davis, C.R., Crowell, J.A., and Mantzoros, C.S. 2014. Diet quality is associated with circulating C-reactive protein but not irisin levels in humans. Metabolism, 63: 233-41. doi: 10.1016/j.metabol.2013.10.011. PMID: 24315778.

Pekkala, S., Wiklund, P.K., Hulmi, J.J., Ahtiainen, J.P., Horttanainen, M., Pollanen, E., et al. 2013. Are skeletal muscle FNDC5 gene expression and irisin release regulated by exercise 
and related to health? J. Physiol. 591: 5393-400. doi: 10.1113/jphysiol.2013.263707. PMID: 24000180.

Powers, S.K., Criswell, D., Lawler, J., Martin, D., Lieu, F.K., Ji, L.L., et al. 1993. Rigorous exercise training increases superoxide dismutase activity in ventricular myocardium. Am. J. Physiol. 265: H2094-8. doi: 10.1152/ajpheart.1993.265.6.H2094. PMID: 8285249.

Reinehr, T., Elfers, C., Lass, N., and Roth, C.L. 2015. Irisin and its relation to insulin resistance and puberty in obese children: a longitudinal analysis. J. Clin. Endocrinol. Metab. 100: 2123-30. doi: 10.1210/jc.2015-1208. PMID: 25781361.

Roca-Rivada, A., Castelao, C., Senin, L.L., Landrove, M.O., Baltar, J., Belen Crujeiras, A., et al. 2013. FNDC5/irisin is not only a myokine but also an adipokine. PLoS One, 8: e60563. doi: 10.1371/journal.pone.0060563. PMID: 23593248.

Rodriguez, A., Becerril, S., Ezquerro, S., Mendez-Gimenez, L., and Fruhbeck, G. 2017. Crosstalk between adipokines and myokines in fat browning. Acta. Physiol. (Oxf.) 219: 362381. doi: 10.1111/apha.12686. PMID: 27040995.

Sanchis-Gomar, F., Alis, R., Pareja-Galeano, H., Sola, E., Victor, V.M., Rocha, M., et al. 2014. Circulating irisin levels are not correlated with BMI, age, and other biological parameters in obese and diabetic patients. Endocrine, 46: 674-7. doi: 10.1007/s12020-0140170-9. PMID: 24510629.

Sawada, N., Jiang, A., Takizawa, F., Safdar, A., Manika, A., Tesmenitsky, Y., et al. 2014. Endothelial PGC-1alpha mediates vascular dysfunction in diabetes. Cell. Metab. 19: 246-58. doi: 10.1016/j.cmet.2013.12.014. PMID: 24506866.

Schlogl, M., Piaggi, P., Votruba, S.B., Walter, M., Krakoff, J., and Thearle, M.S. 2015. Increased 24-hour ad libitum food intake is associated with lower plasma irisin concentrations the following morning in adult humans. Appetite, 90: 154-9. doi: 10.1016/j.appet.2015.03.003. PMID: 25765248. 
Seale, P., Kajimura, S., Yang, W., Chin, S., Rohas, L.M., Uldry, M., et al. 2007. Transcriptional control of brown fat determination by PRDM16. Cell. Metab. 6: 38-54. doi: 10.1016/j.cmet.2007.06.001. PMID: 17618855 .

Seo, D.Y., Kwak, H.B., Lee, S.R., Cho, Y.S., Song, I.S., Kim, N., et al. 2014. Effects of aged garlic extract and endurance exercise on skeletal muscle FNDC-5 and circulating irisin in high-fat-diet rat models. Nutr. Res. Pract. 8: 177-82. doi: 10.4162/nrp.2014.8.2.177. PMID: 24741402.

Sesti, G., Andreozzi, F., Fiorentino, T.V., Mannino, G.C., Sciacqua, A., Marini, M.A., et al. 2014. High circulating irisin levels are associated with insulin resistance and vascular atherosclerosis in a cohort of nondiabetic adult subjects. Acta Diabetol. 51: 705-13. doi: 10.1007/s00592-014-0576-0. PMID: 24619655.

Sharma, N., Castorena, C.M., and Cartee, G.D. 2012. Greater insulin sensitivity in calorie restricted rats occurs with unaltered circulating levels of several important myokines and cytokines. Nutr. Metab. (Lond.) 9: 90. doi: 10.1186/1743-7075-9-90. PMID: 23067400.

Sparks, L.M., Xie, H., Koza, R.A., Mynatt, R., Hulver, M.W., Bray, G.A., et al. 2005. A high-fat diet coordinately downregulates genes required for mitochondrial oxidative phosphorylation in skeletal muscle. Diabetes, 54: 1926-33. PMID: 15983191.

Srinivasa, S., Suresh, C., Mottla, J., Hamarneh, S.R., Irazoqui, J.E., Frontera, W., et al. 2016. FNDC5 relates to skeletal muscle IGF-I and mitochondrial function and gene expression in obese men with reduced growth hormone. Growth Horm. IGF. Res. 26: 36-41. doi: 10.1016/j.ghir.2015.12.008. PMID: 26774404.

Stengel, A., Hofmann, T., Goebel-Stengel, M., Elbelt, U., Kobelt, P., and Klapp, B.F. 2013. Circulating levels of irisin in patients with anorexia nervosa and different stages of obesity-correlation with body mass index. Peptides, 39: 125-30. doi: 10.1016/j.peptides.2012.11.014. PMID: 23219488. 
Timmons, J.A., Baar, K., Davidsen, P.K., and Atherton, P.J. 2012. Is irisin a human exercise gene? Nature, 488: E9-10; discussion E10-1. doi: 10.1038/nature11364. PMID: 22932392.

Wen, M.S., Wang, C.Y., Lin, S.L., and Hung, K.C. 2013. Decrease in irisin in patients with chronic kidney disease. PLoS One, 8: e64025. doi: 10.1371/journal.pone.0064025. PMID: 23667695.

Wu, M.V., Bikopoulos, G., Hung, S., and Ceddia, R.B. 2014. Thermogenic capacity is antagonistically regulated in classical brown and white subcutaneous fat depots by high fat diet and endurance training in rats: impact on whole-body energy expenditure. J. Biol. Chem. 289: 34129-40. doi: 10.1074/jbc.M114.591008. PMID: 25344623.

Zhang, Y., Li, R., Meng, Y., Li, S., Donelan, W., Zhao, Y., et al. 2014. Irisin stimulates browning of white adipocytes through mitogen-activated protein kinase p38 MAP kinase and ERK MAP kinase signaling. Diabetes, 63: 514-25. doi: 10.2337/db13-1106. PMID: 24150604. 
Table 1. Two-way ANOVA for WAT/body weight, BAT/body weight, RNA expression, protein content of PGC-1 $\alpha$, FNDC5, mitochondria and Irisin

\begin{tabular}{|c|c|c|c|c|c|c|c|}
\hline \multirow[t]{2}{*}{ Parameters } & \multicolumn{3}{|c|}{ Main effect } & \multicolumn{4}{|c|}{ Interaction } \\
\hline & Exercise & Diet & Obesity & Exercise*Diet & Exercise*Obesity & Diet*Obesity & Exercise*Diet*Obesity \\
\hline $\begin{array}{l}\text { \%WAT/body } \\
\text { weight }\end{array}$ & $p<0.05^{*}$ & $p<0.001 *$ & $p>0.05$ & $p<0.05^{*}$ & $p>0.05$ & $p>0.05$ & $p>0.05$ \\
\hline $\begin{array}{l}\% \text { BAT/body } \\
\text { weight }\end{array}$ & $p<0.001^{*}$ & $p<0.05^{*}$ & $p<0.001^{*}$ & $p>0.05$ & $p>0.05$ & $p>0.05$ & $p>0.05$ \\
\hline $\begin{array}{l}\text { Vis. WAT } \\
P g c-1 \alpha m R N A\end{array}$ & $p>0.05$ & $p>0.05$ & $p<0.05^{*}$ & $p>0.05$ & $p>0.05$ & $p>0.05$ & $p<0.01^{*}$ \\
\hline $\begin{array}{l}\text { Vis. WAT Fndc5 } \\
m R N A\end{array}$ & $p>0.05$ & $p>0.05$ & $p<0.01^{*}$ & $p>0.05$ & $p>0.05$ & $p>0.05$ & $p<0.05^{*}$ \\
\hline $\begin{array}{l}\text { Muscle } P g c- \\
1 \alpha m R N A\end{array}$ & $p>0.05$ & $p<0.001^{*}$ & $p<0.001^{*}$ & $p<0.001^{*}$ & $p<0.05^{*}$ & $p>0.05$ & $p<0.001^{*}$ \\
\hline $\begin{array}{l}\text { Muscle } \\
\text { PGC-1 } \alpha / G A P D H \\
\text { protein }\end{array}$ & $p<0.001^{*}$ & $p<0.001^{*}$ & $p<0.001^{*}$ & $p<0.001^{*}$ & $p<0.001^{*}$ & $p<0.001^{*}$ & $p>0.05$ \\
\hline $\begin{array}{l}\text { Muscle } \\
\text { mitochondria } \\
\text { protein }\end{array}$ & $p<0.001^{*}$ & $p<0.001 *$ & $p<0.001^{*}$ & $p<0.001^{*}$ & $p<0.001^{*}$ & $p<0.001 *$ & $p<0.001^{*}$ \\
\hline $\begin{array}{l}\text { Muscle Fndc5 } \\
m R N A\end{array}$ & $p>0.05$ & $p<0.001^{*}$ & $p<0.05^{*}$ & $p<0.05^{*}$ & $p>0.05$ & $p<0.01^{*}$ & $p<0.05^{*}$ \\
\hline $\begin{array}{l}\text { Muscle } \\
\text { FNDC5/GAPDH } \\
\text { protein }\end{array}$ & $p<0.001^{*}$ & $p<0.001^{*}$ & $p>0.05$ & $p<0.001^{*}$ & $p<0.001^{*}$ & $p>0.05$ & $p<0.05^{*}$ \\
\hline $\begin{array}{l}\text { Muscle Ucpl } \\
\text { mRNA }\end{array}$ & $p<0.05^{*}$ & $p<0.001^{*}$ & $p<0.001^{*}$ & $p>0.05$ & $p>0.05$ & $p<0.001^{*}$ & $p>0.05$ \\
\hline Irisin $(\mathrm{ng} / \mathrm{mL})$ & $p>0.05$ & $p>0.05$ & $p<0.05^{*}$ & $p>0.05$ & $p>0.05$ & $p>0.05$ & $p>0.05$ \\
\hline
\end{tabular}

Differences between \%WAT/body weight, \%BAT/body weight, Pgc-1 $\alpha$, Fndc5, Ucp1 RNA expression and protein content of PGC-1 $\alpha$, FNDC5 and mitochondria and plasma irisin in all groups are shown to be significant at $\mathrm{p}<0.05 . *$ represents significant difference between groups. 


\section{Figure Legends:}

Figure 1. Body weight monitored throughout the treatment diet and exercise. A schematic representation of the protocol with two interventions used for this study (A). Changes in body weight in mice following the administration different diets in the first intervention (B). Changes in body weight in the obese mice (HF fed mice in the 1st intervention) following the administration of diet and exercise in the second intervention (C). Changes in body weight in the non-obese mice (LF fed mice in 1st intervention) following the administration of diet and exercise in second intervention (D). All data are shown as mean \pm SEM, $n=6$ per group. Statistical significance designated on graphs as follows: *** represents significant difference at $p<0.001$.

Figure 2. The effects of obesity, diet and exercise on the \%white adipose tissue (WAT)/body weight and the \%brown adipose tissue (BAT)/body weight. The effects of diet and exercise on the WAT/body weight (\%) in obese and non-obese mice (A). The effects of diet and exercise on the BAT/body weight (\%) in the obese and non-obese mice (B). The effects of obesity, diet and exercise on the WAT/body weight (\%) with two-way ANOVA (C). The effects of obesity, diet and exercise on the BAT/body weight (\%) with two-way ANOVA (D). All data are mean \pm SEM, $n=6$ per group. (a), (b) and (c) represent significant difference between the same indicated samples for diet, exercise and obesity effects respectively calculated by two-way ANOVA. 
Figure 3. The effects of obesity, diet and exercise on the expression levels of $P g c-1 \alpha$ and Fndc5 in the vis. WAT normalized with transcript level of Gapdh. Relative expression of vis. WAT $P g c-1 \alpha$ in the obese mice and non-obese mice (A). Transcript levels of vis. WAT Fndc5 in the obese mice and non-obese mice (B). The effects of obesity, diet and exercise on transcript levels of Pgc-1 $\alpha$ in vis. WAT with two-way ANOVA (C). The effects of obesity, diet and exercise on the transcript levels of Fndc5 in the vis. WAT with two-way ANOVA (D). All data are mean \pm SEM, $n=6$ per group. (c) represents significant difference between the same indicated samples for obesity effect calculated by two-way ANOVA.

Figure 4. The effects of obesity, diet and exercise on PGC-1 $\alpha$ mRNA and protein in skeletal muscle relative to GAPDH. Relative expression of $P g c-1 \alpha$ in the obese and non-obese mice (A). Skeletal muscle protein levels of $P g c-1 \alpha$ in the obese and non-obese mice (B). The effects of obesity, diet and exercise on transcript levels of Pgc-1 $\alpha$ in the skeletal muscle with two-way ANOVA (C). The effects of obesity, diet and exercise on the protein levels of Pgc$1 \alpha$ in the skeletal muscle with two-way ANOVA (D). All data are shown as mean \pm SEM, $\mathrm{n}=6$ per group. (a), (b) and (c) represent significant difference between the same indicated samples for diet, exercise and obesity effects respectively calculated by two-way ANOVA.

Figure 5. The effects of obesity, diet and exercise on FNDC5 mRNA and protein in skeletal muscle relative to GAPDH. Relative expression of Fndc5 in the obese and non-obese mice (A). Skeletal muscle protein levels of FNDC5 in the obese and non-obese mice (B). The effects of obesity, diet and exercise on transcript levels of Fndc5 in the skeletal muscle with two-way ANOVA (C). The effects of obesity, diet and exercise on the protein levels of FNDC5 in the skeletal muscle with two-way ANOVA (D). All data are shown as mean \pm SEM, $n=6$ per group. (a), (b) and (c) represent significant difference between the same 
indicated samples for diet, exercise and obesity effects respectively calculated by two-way ANOVA.

Figure 6. The effects of obesity, diet and exercise on mitochondrial protein of skeletal muscle. Protein levels of mitochondria from Skeletal muscle in the obese and non-obese mice (A). The effects of obesity, diet and exercise on protein levels of mitochondria in the skeletal muscle with two-way ANOVA (B). All data are shown as mean \pm SEM, $n=6$ per group. (a), (b) and (c) represent significant difference between the same indicated samples for diet, exercise and obesity effects respectively calculated by two-way ANOVA.

Figure 7. The effects of obesity, diet and exercise on mRNA levels of Ucpl in the skeletal muscle relative to GAPDH. Relative expression of Ucpl in the obese and non-obese mice (A). The effects of obesity, diet and exercise on transcript levels of Ucpl in the skeletal muscle with two-way ANOVA (B). All data are shown as mean \pm SEM, $n=6$ per group. (a), (b) and (c) represent significant difference between the same indicated samples for diet, exercise and obesity effects respectively calculated by two-way ANOVA.

Figure 8. The effects of obesity, diet and exercise on plasma irisin levels. plasma irisin levels in the obese and non-obese mice (A). The effects of obesity, diet and exercise on plasma irisin with two-way ANOVA. All data are mean \pm SEM, $n=6$ per group. 
(A)

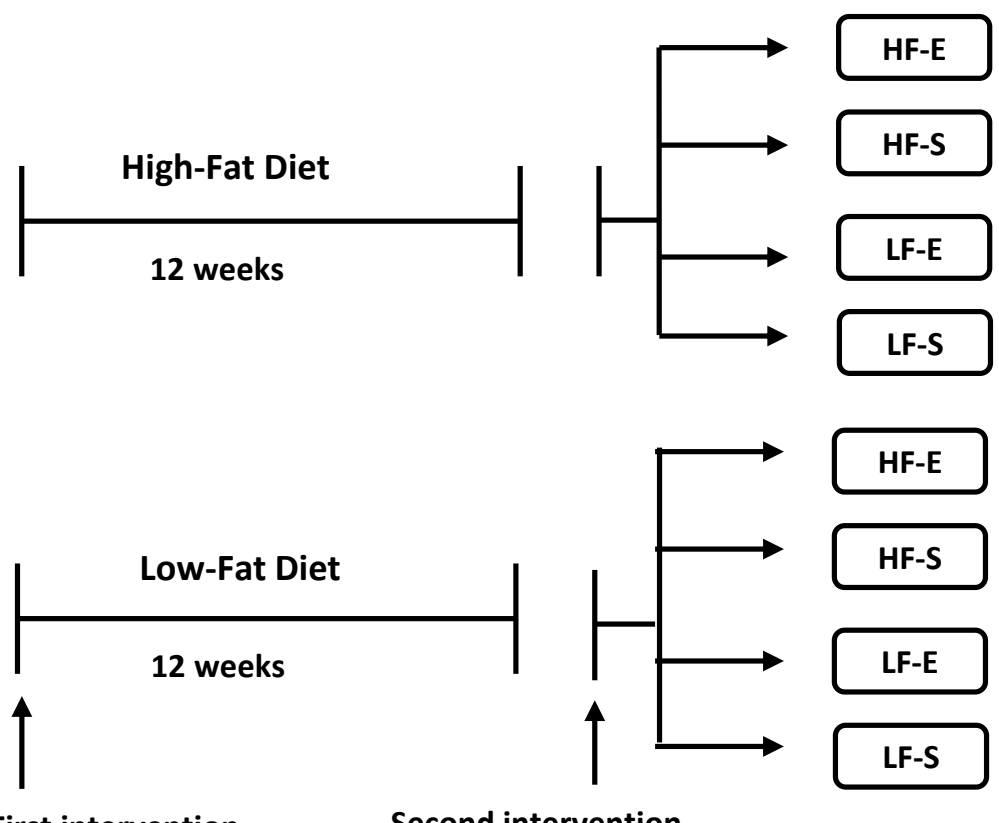

First intervention

Second intervention

(C)

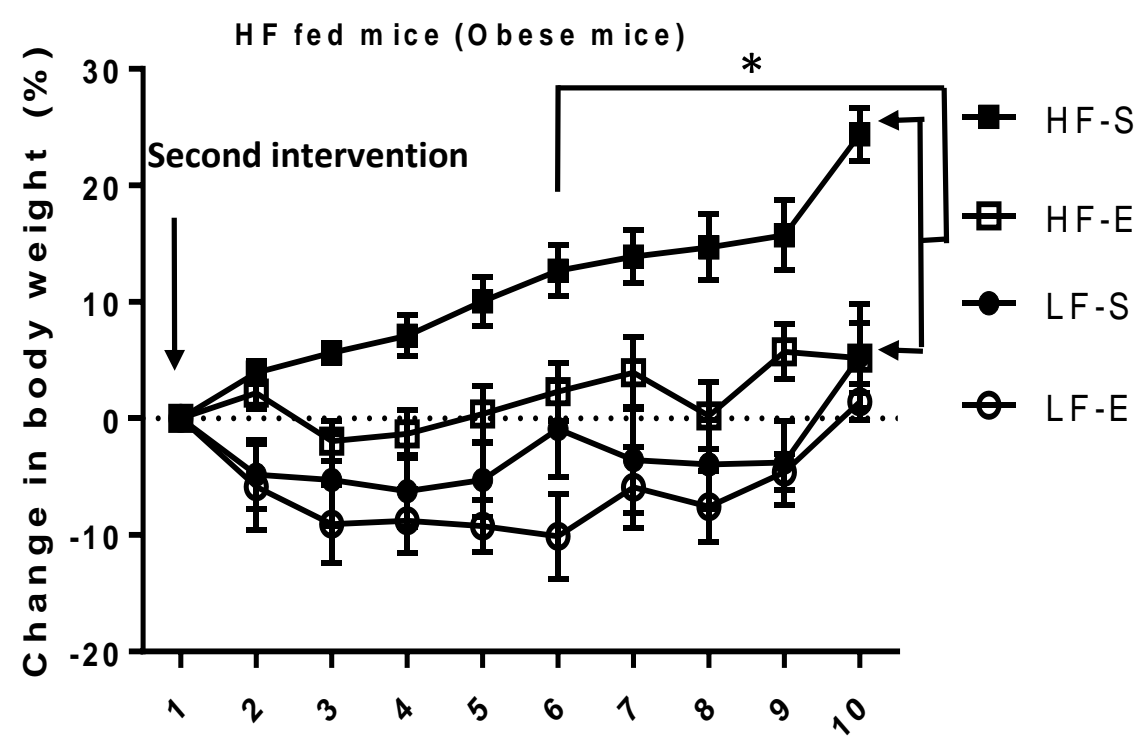

Time (week)
(B)

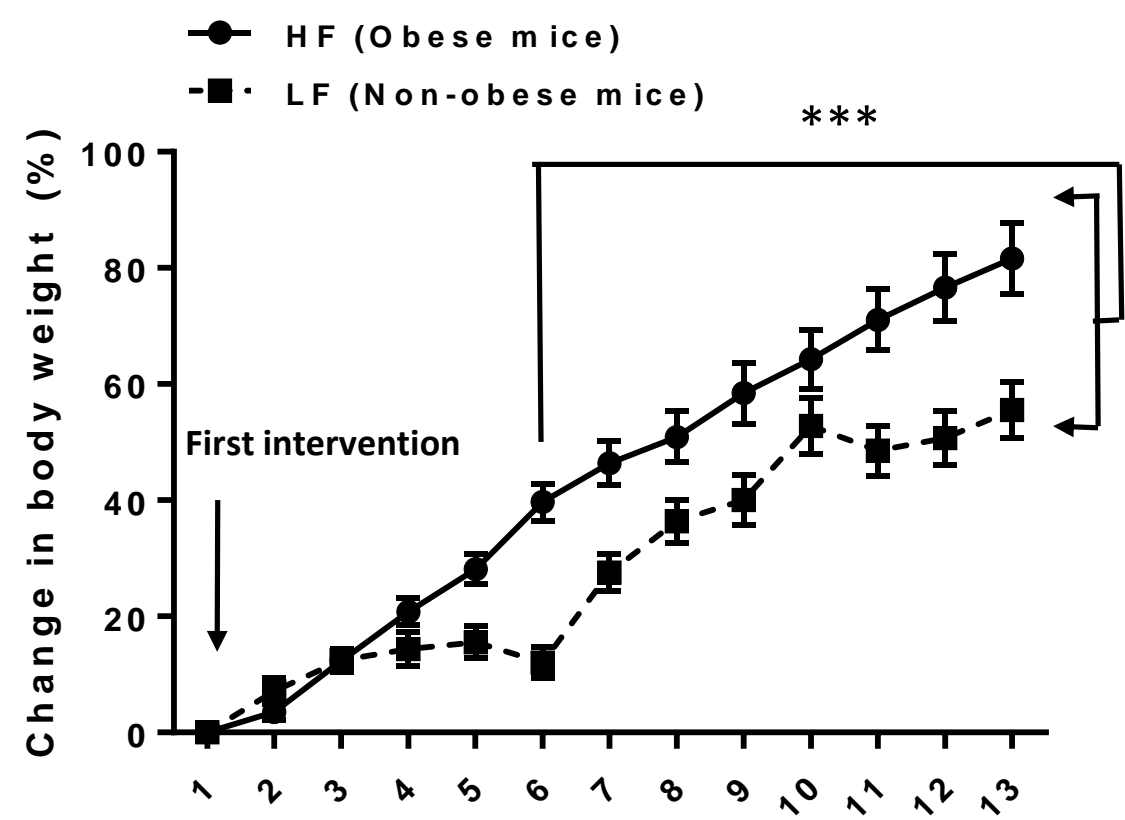

Time (w e e k)

(D)

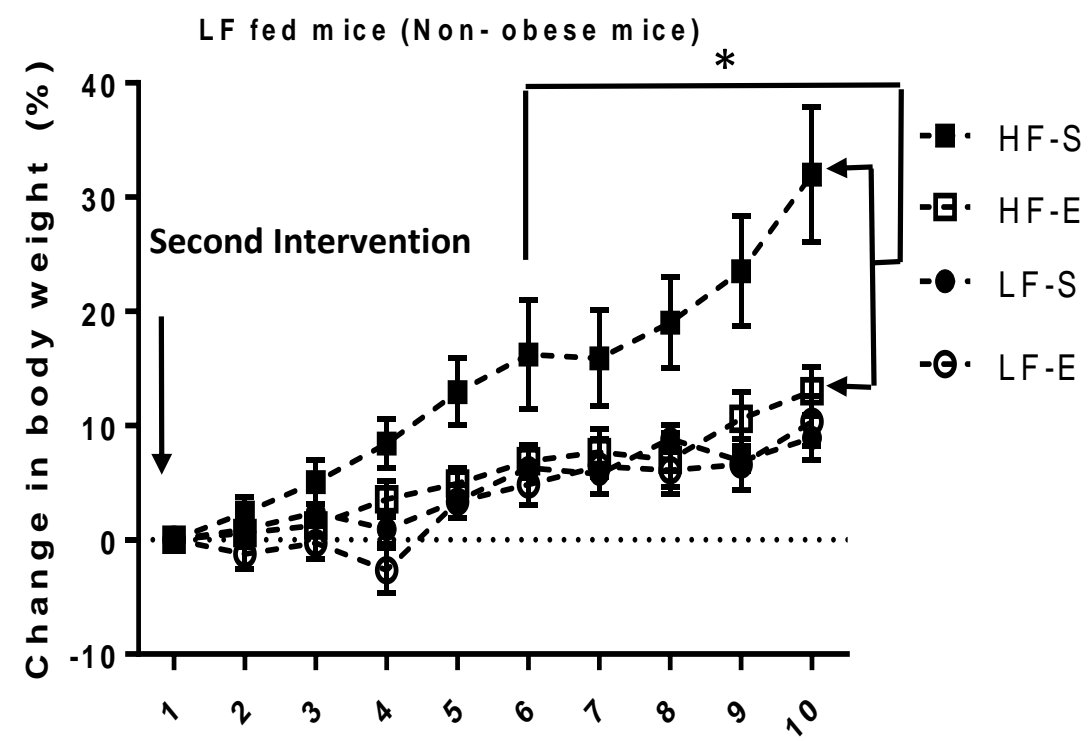

Time (week) 
(A)

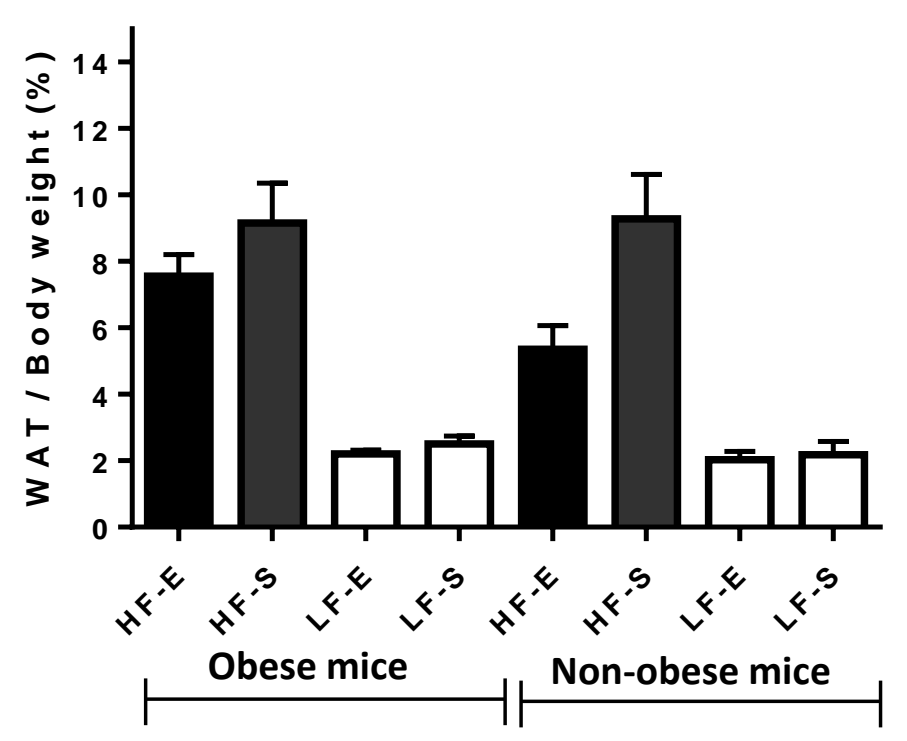

(C)

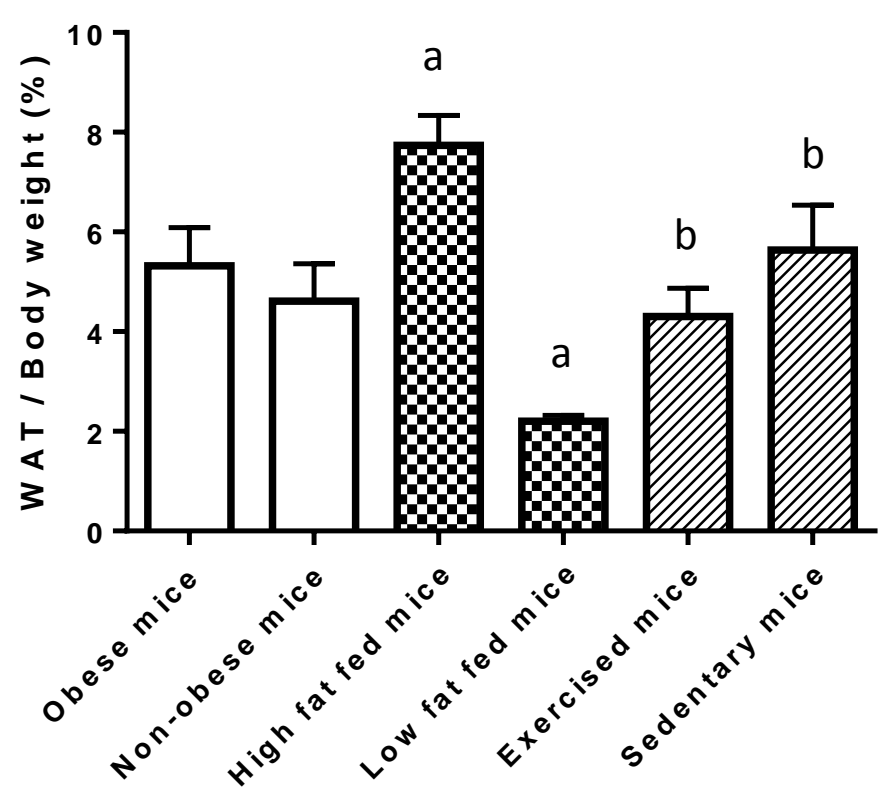

(B)

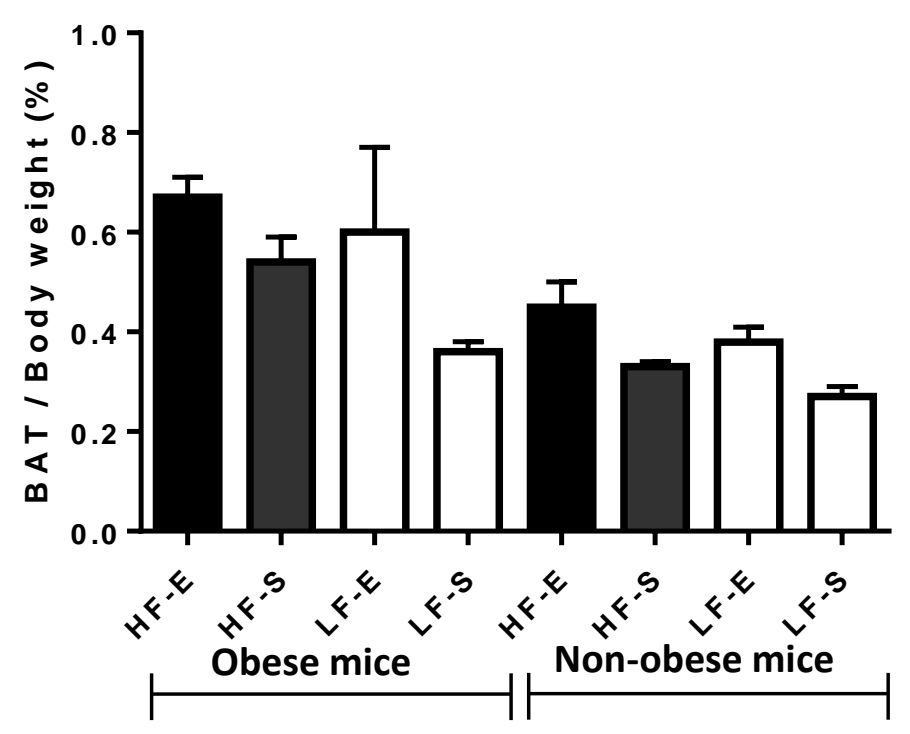

(D)

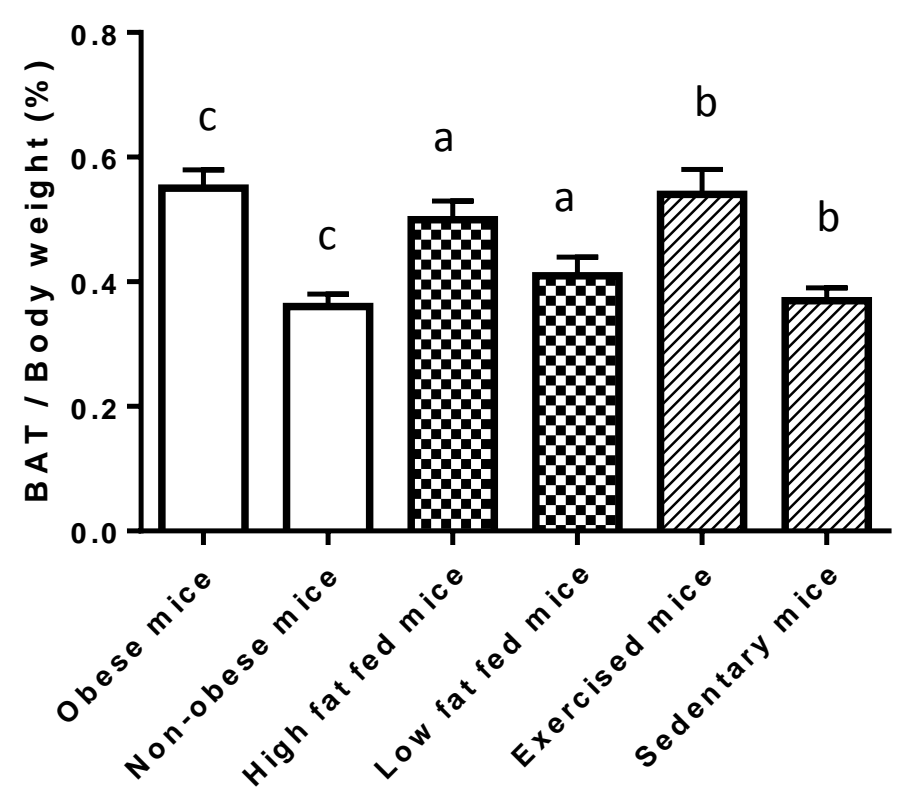


(A)

V is. W A T

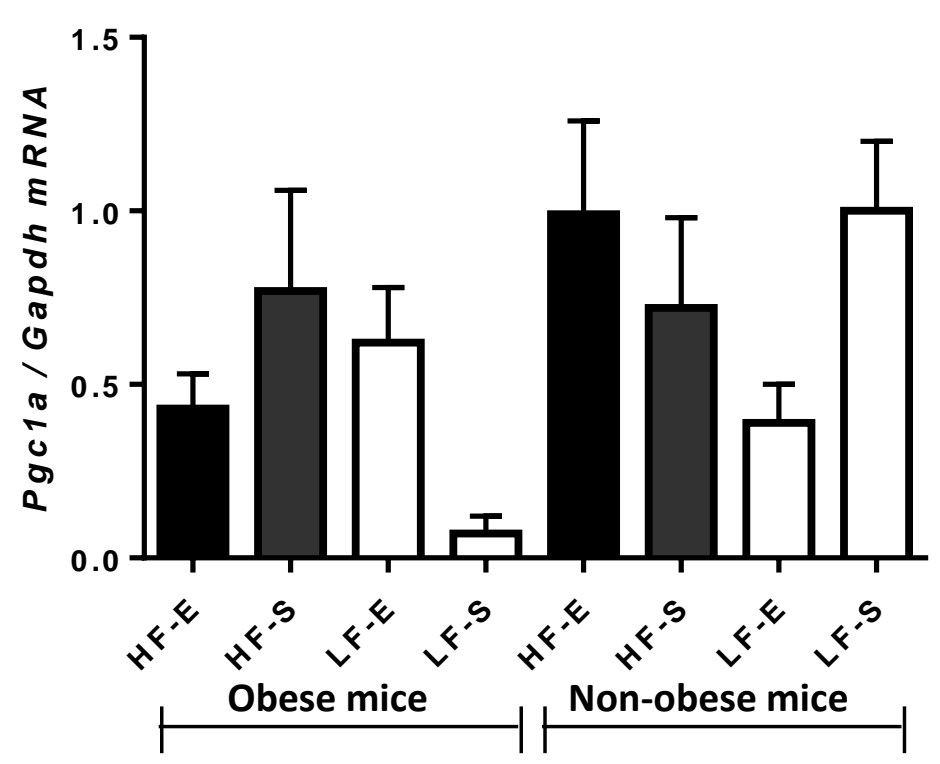

(C)

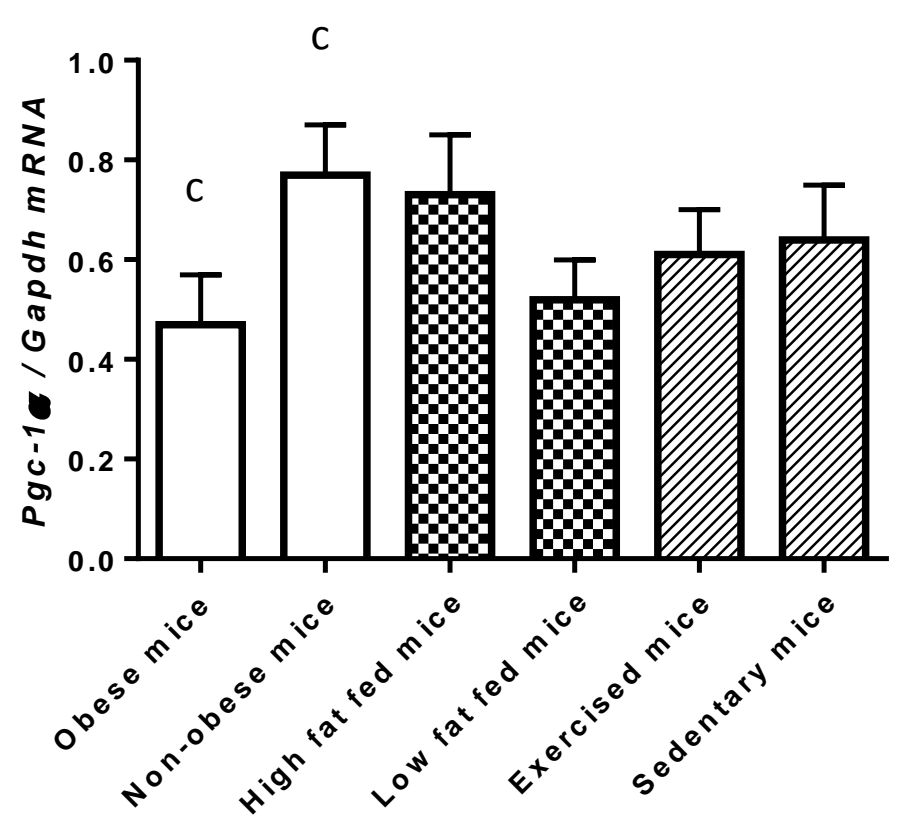

(B)

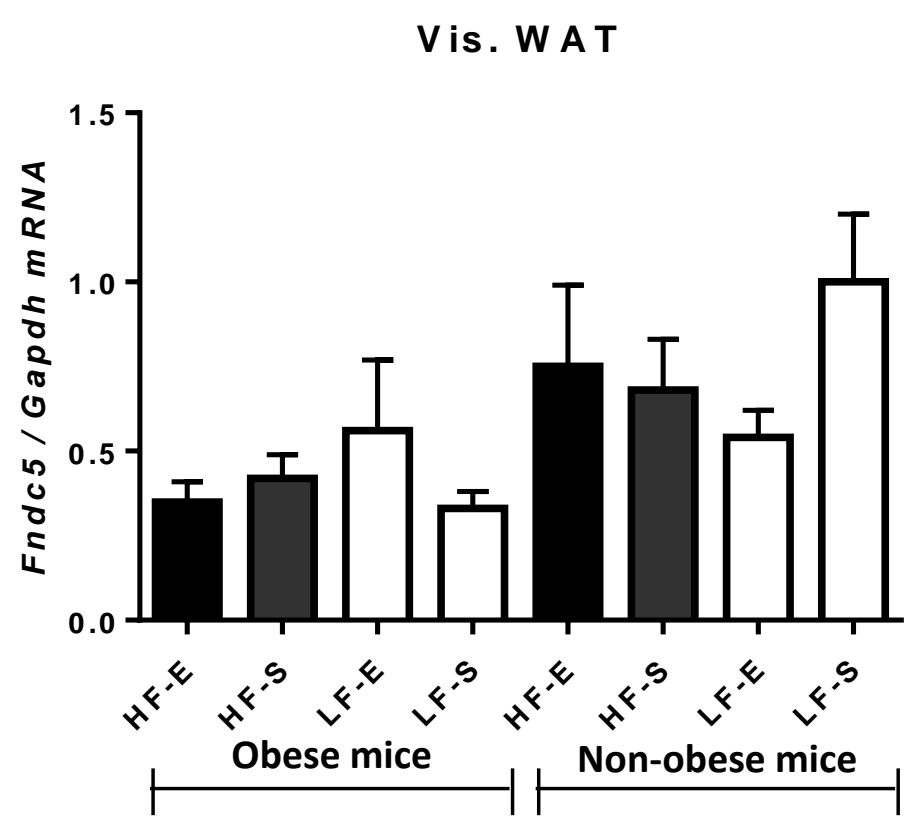

(D)

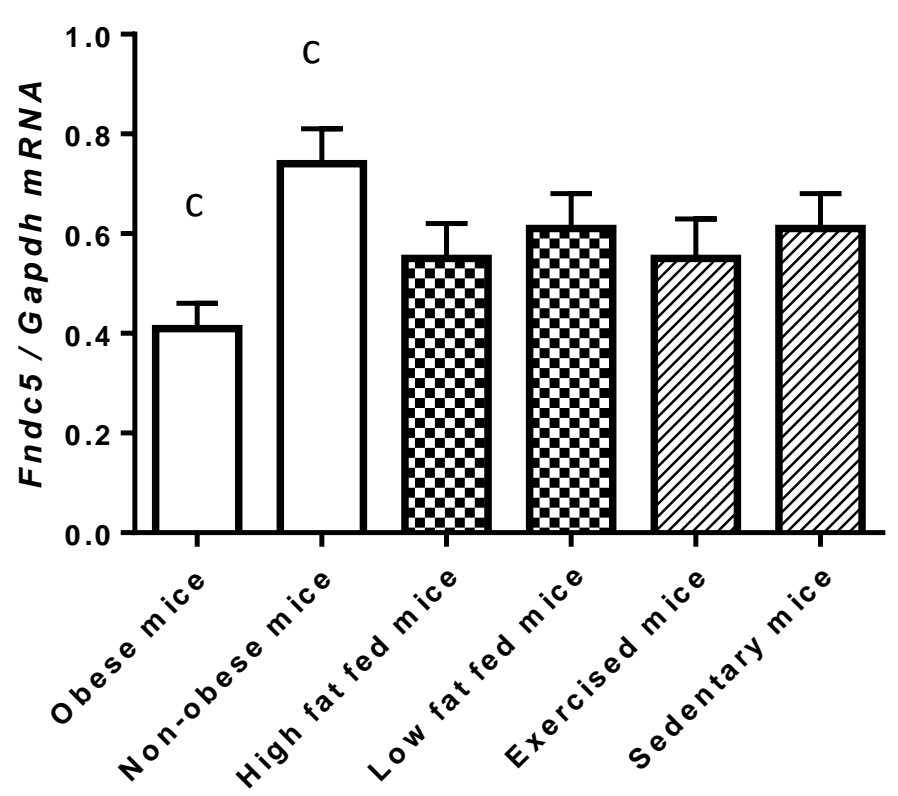


(A)

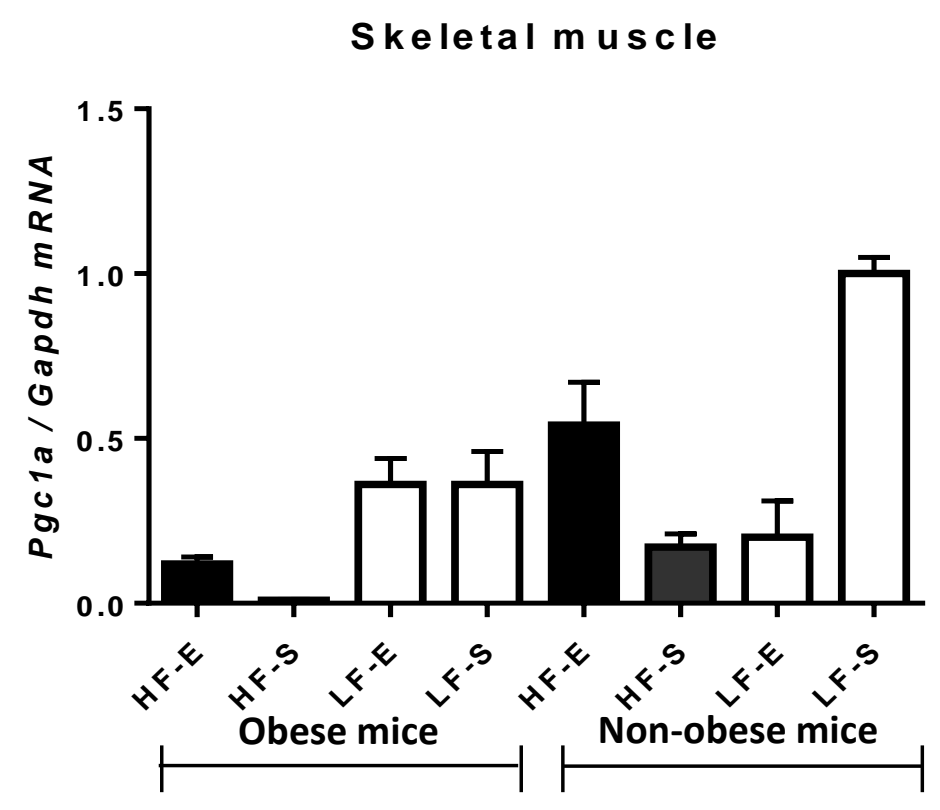

(C)

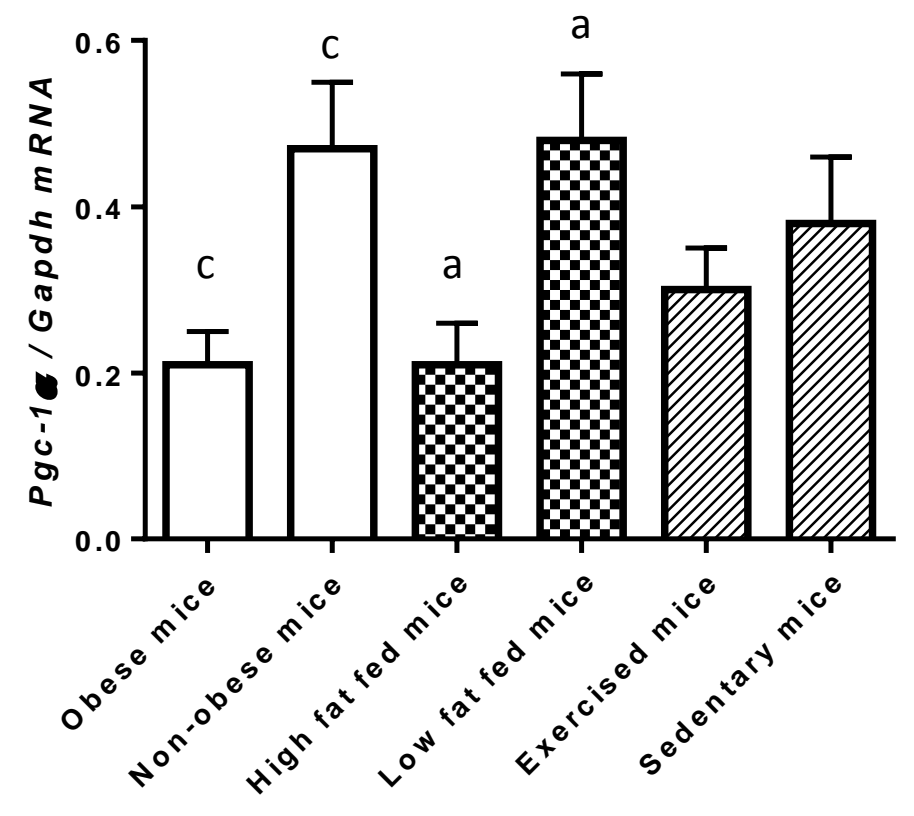

(B) Skeletal muscle

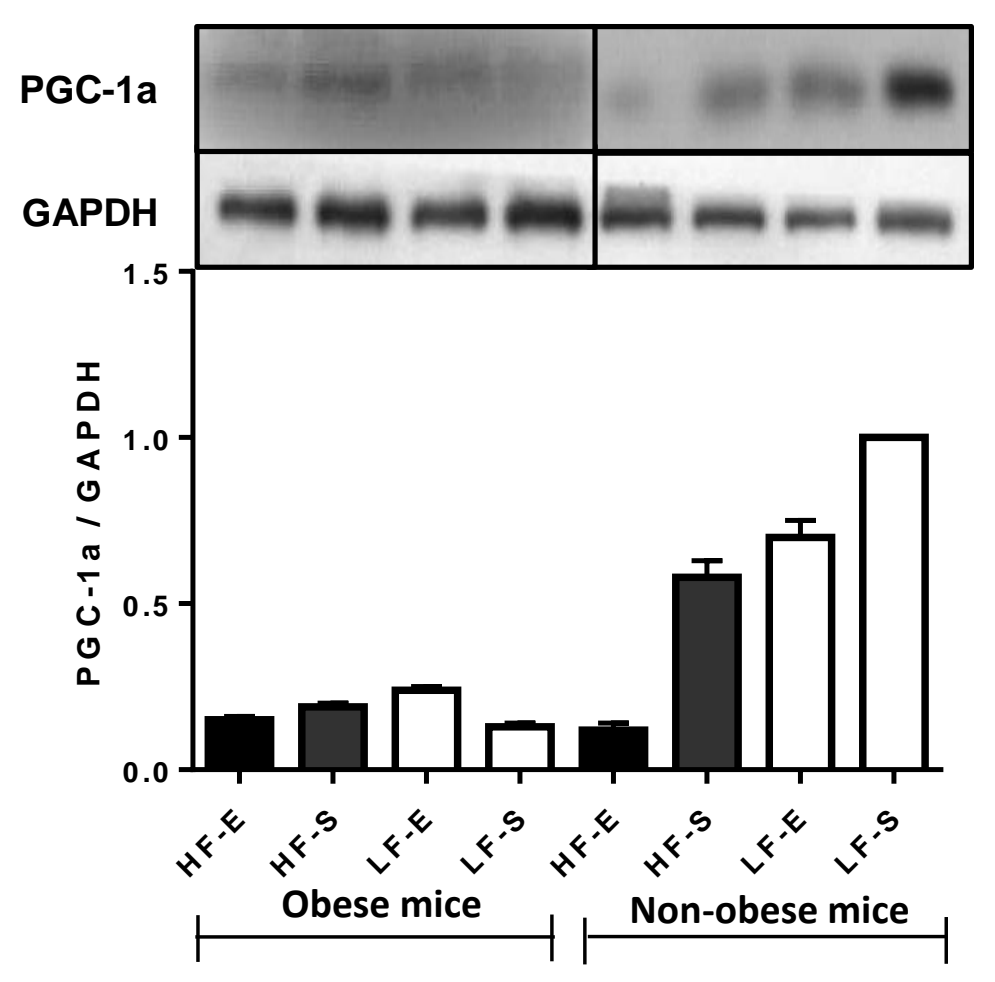

(D)

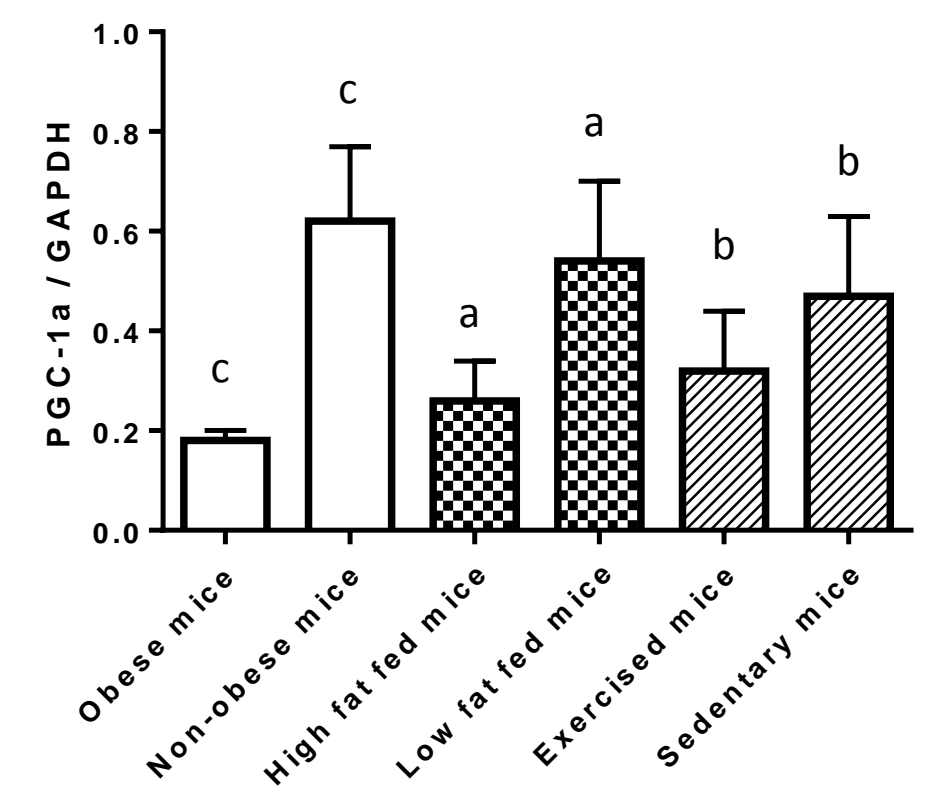


(A)

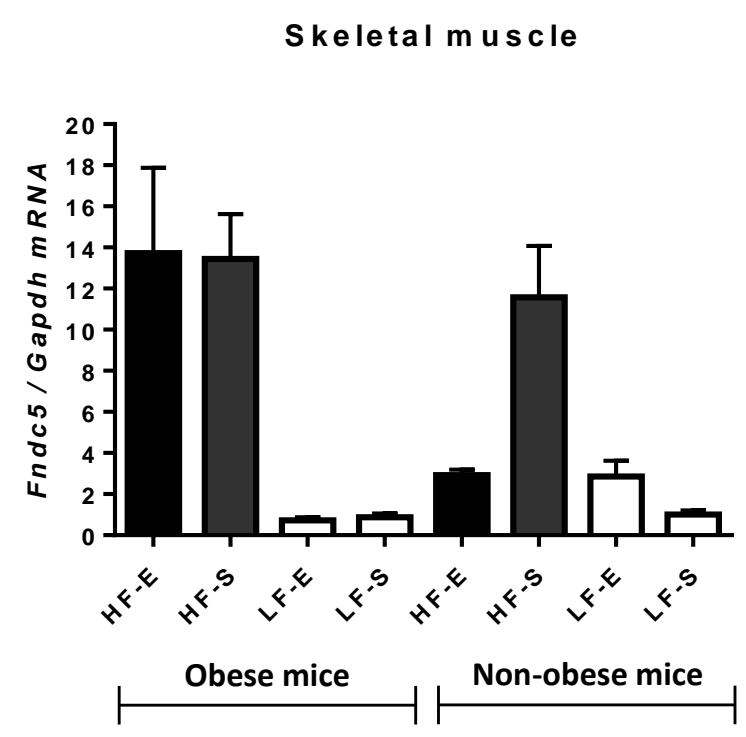

(C)

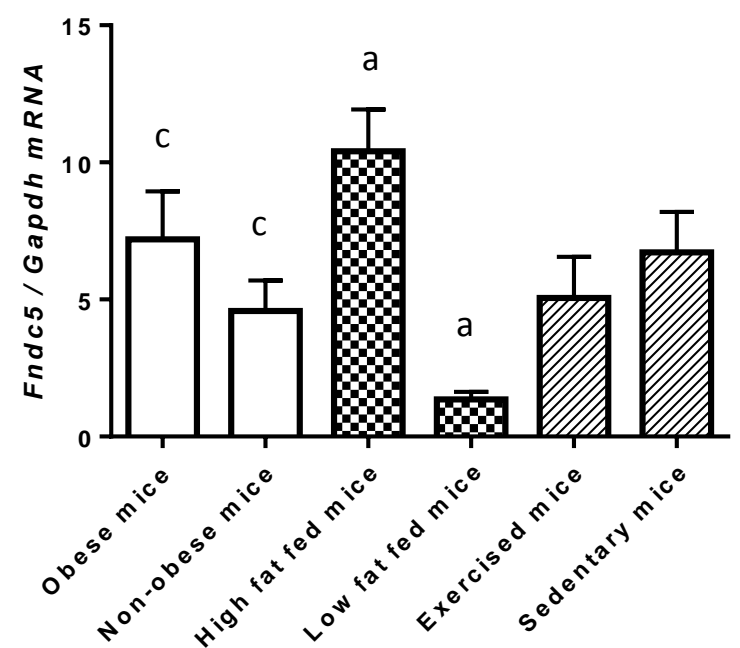

(B)

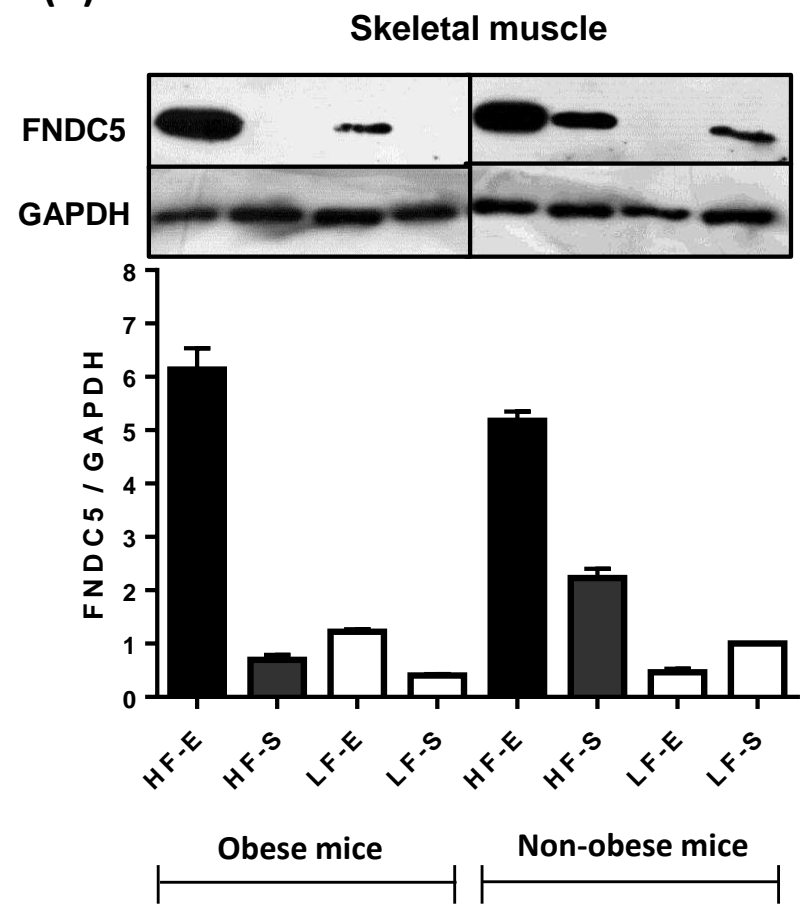

(D)

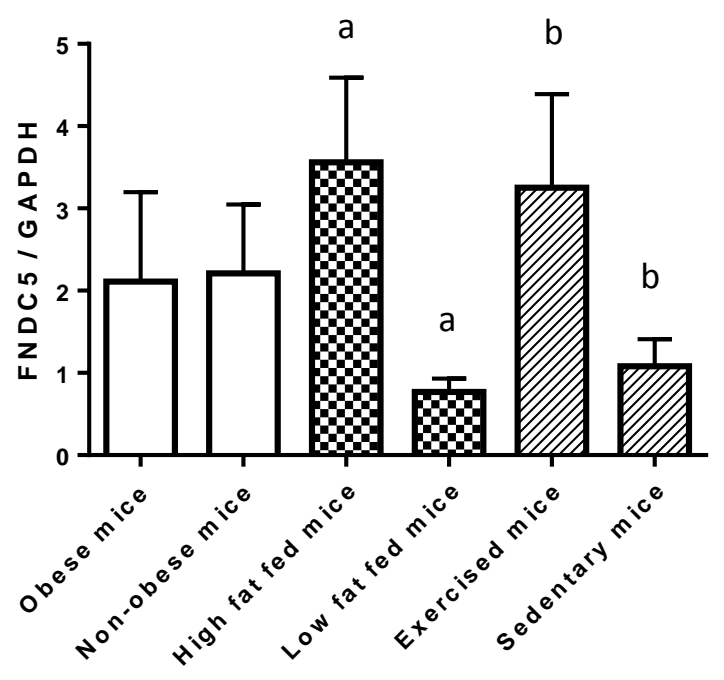


(A)

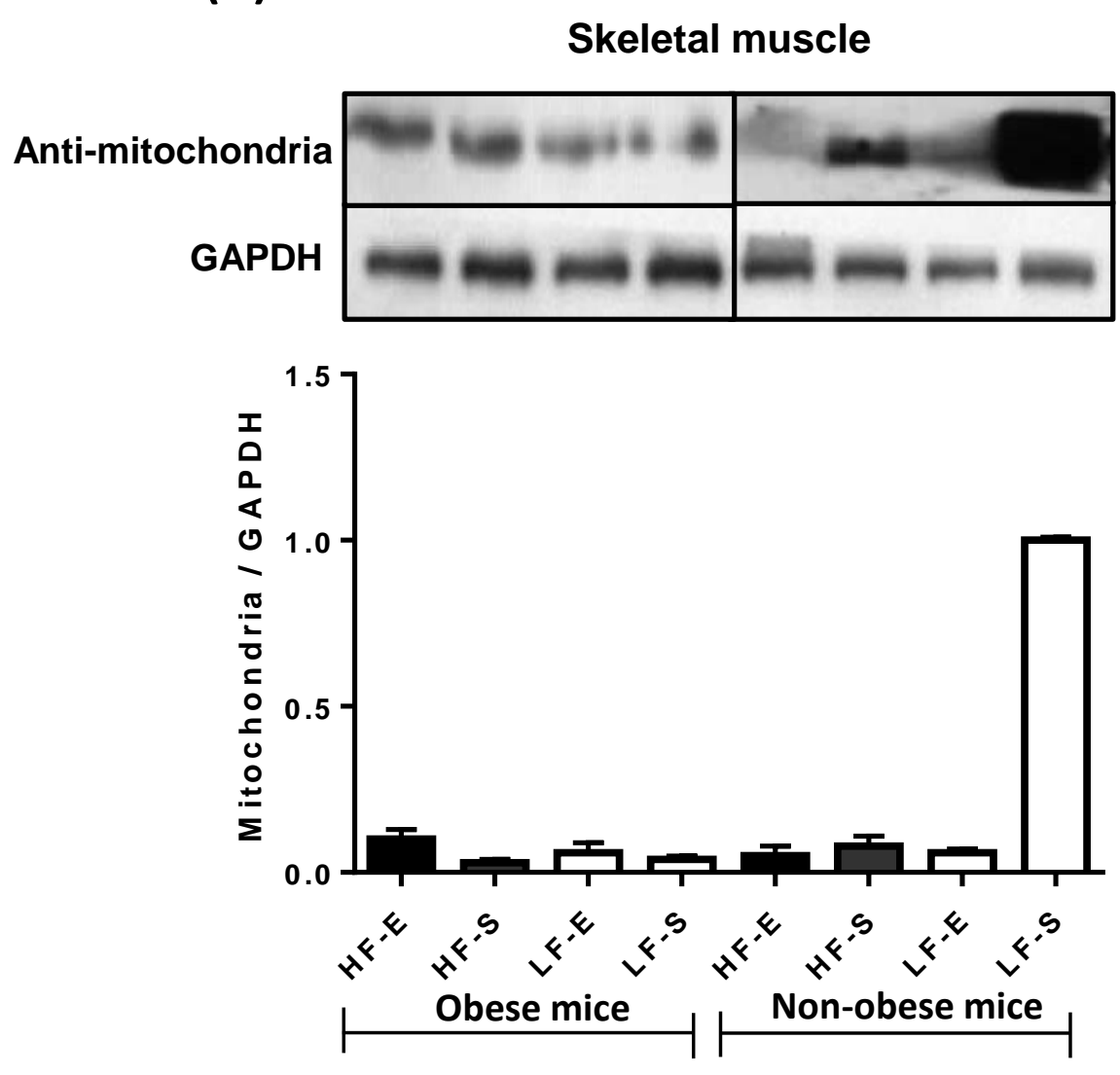

(B)

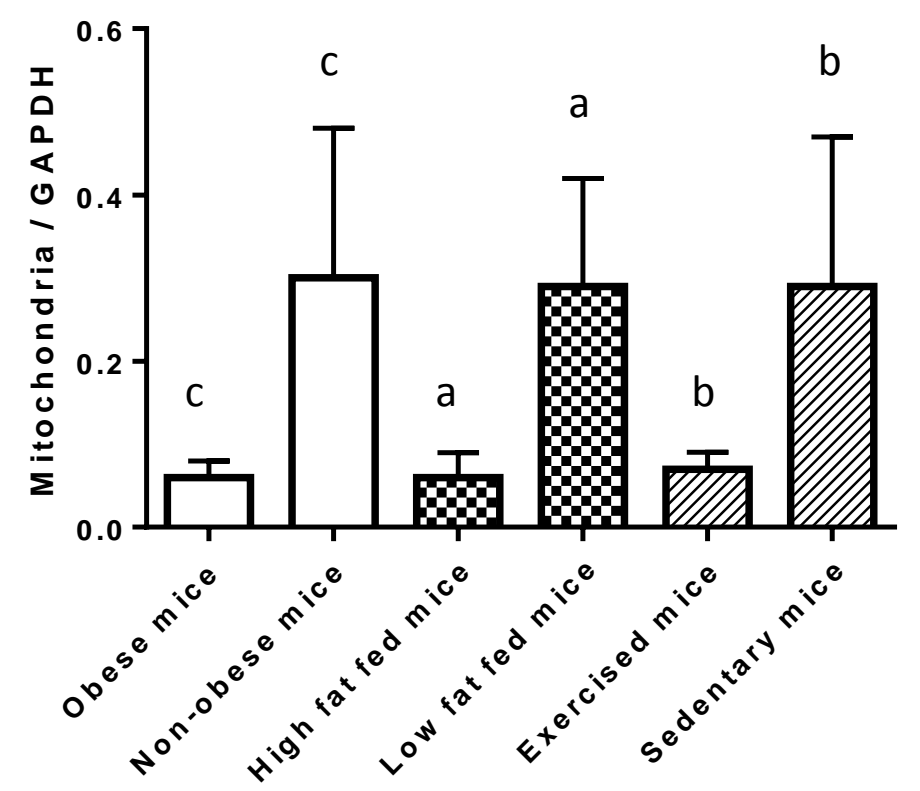


(A)

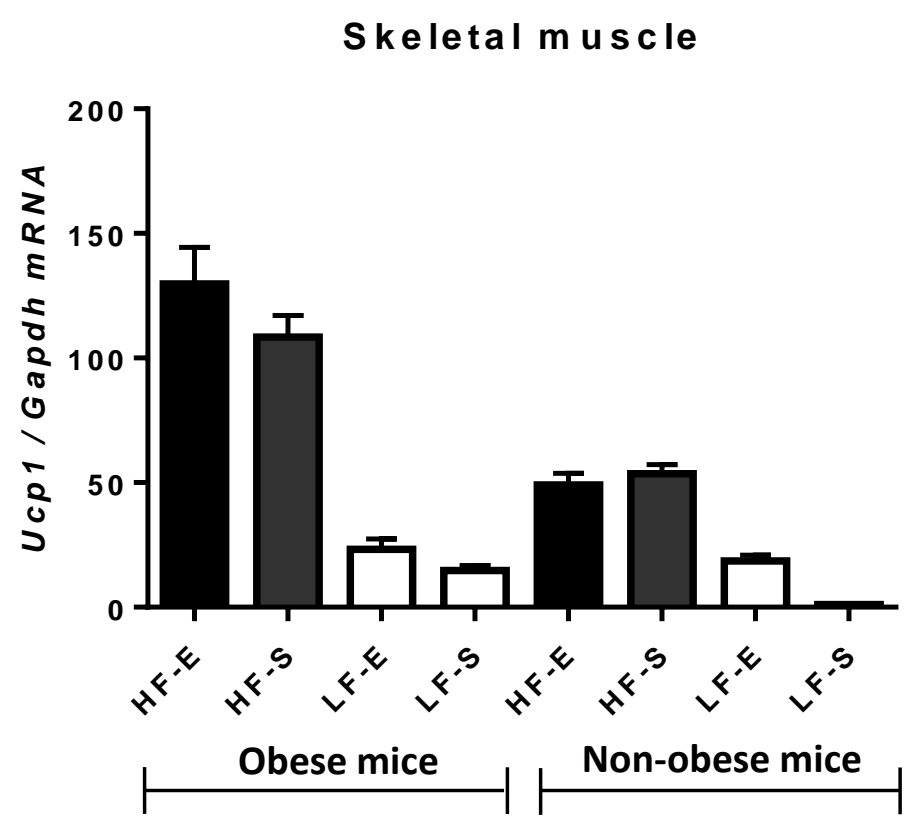

(B)

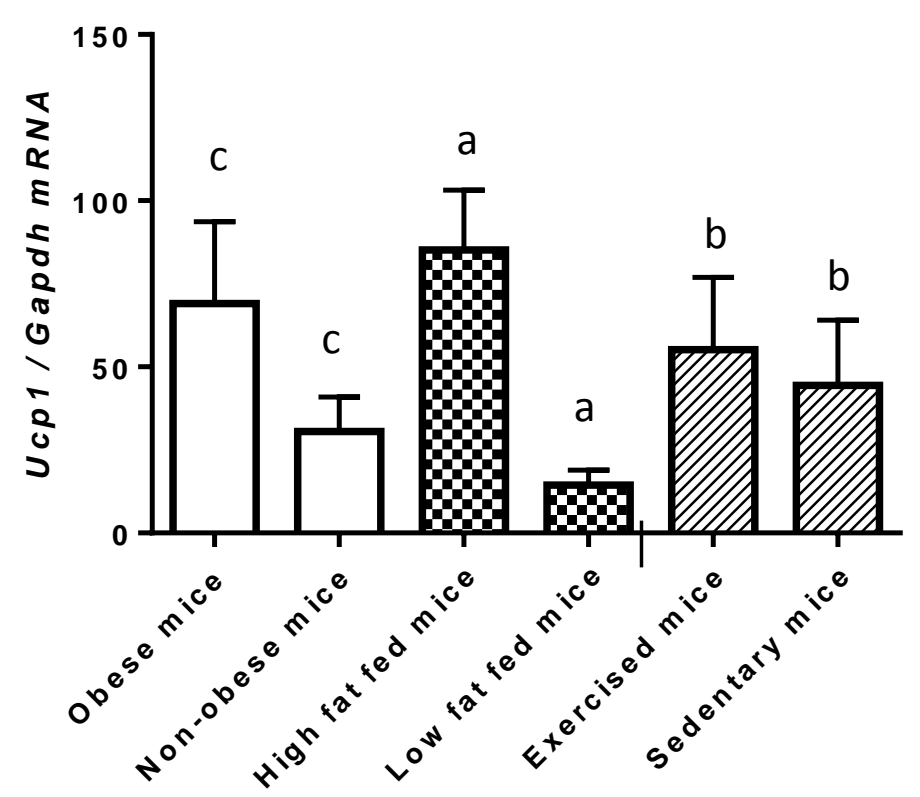


(A)

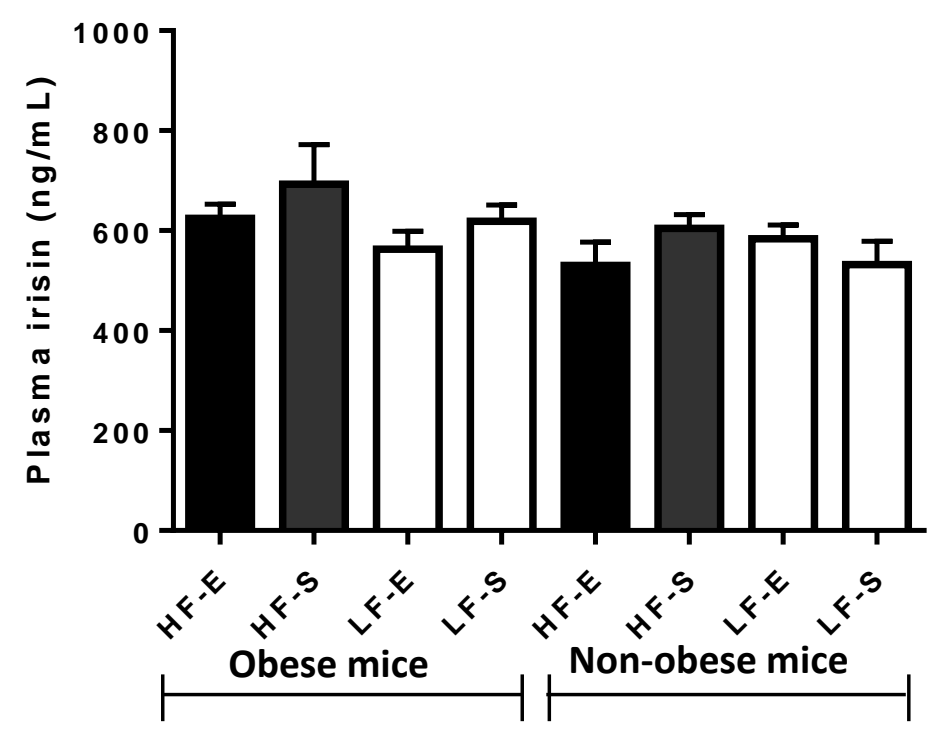

(B)

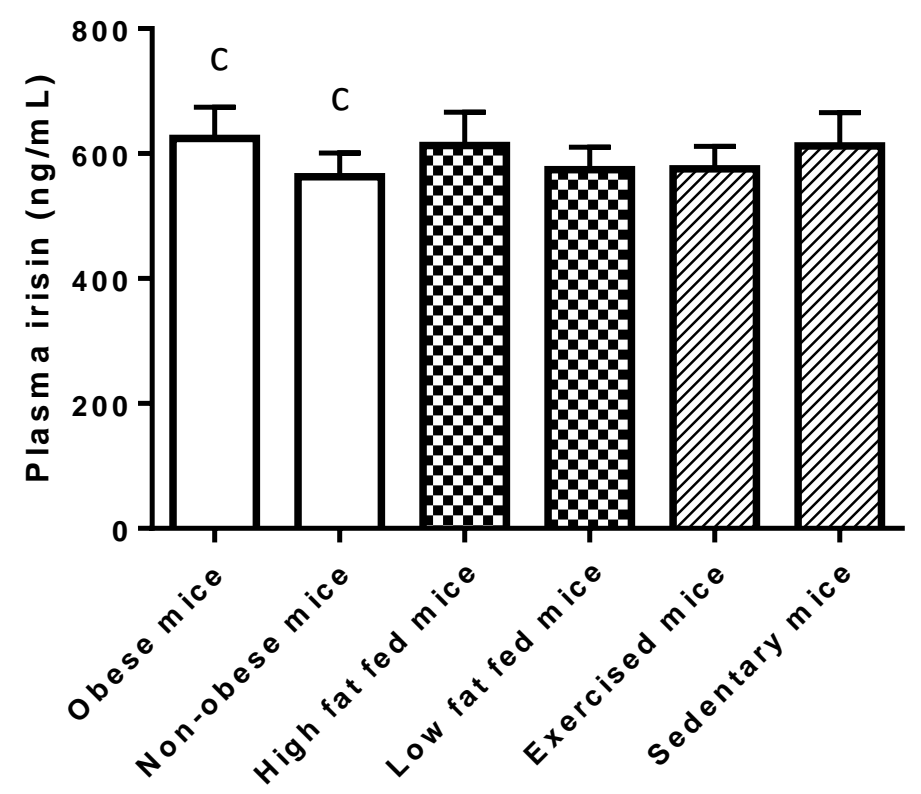

